\title{
Quantification of Inactive Lithium and Solid Electrolyte Interphase (SEI) Species on Graphite Electrodes After Fast Charging
}

Eric J. McShane ${ }^{1,2}$, Andrew M. Colclasure ${ }^{3}$, David E. Brown ${ }^{1,2}$, Zachary M. Konz ${ }^{1,2}$, Kandler Smith $^{3}$, and Bryan D. McCloskey ${ }^{1,2}$

1) Department of Chemical and Biomolecular Engineering, University of California, Berkeley, California 94720, United States

2) Energy Storage and Distributed Resources Division, Lawrence Berkeley National Laboratory, Berkeley, California 94720, United States

3) Transportation and Hydrogen Systems Center, National Renewable Energy Laboratory, Golden, Colorado 80401, United States

\begin{abstract}
Rapid charging of Li-ion batteries is limited by lithium plating on graphite anodes, whereby $\mathrm{Li}^{+}$ions are reduced to $\mathrm{Li}$ metal on the graphite particle surface instead of inserting between graphitic layers. Plated Li metal not only poses a safety risk due to dendrite formation, but also contributes to capacity loss due to the low reversibility of the Li plating/stripping process. Understanding when Li plating occurs and how much Li has plated is therefore vital to remedying these issues. We demonstrate a titration technique with a minimum detection limit of $20 \mathrm{nmol}$ $\left(5 \times 10^{-4} \mathrm{mAh}\right) \mathrm{Li}$ which is used to quantify inactive Li that remains on the graphite electrode after fast charging. Additionally, the titration is extended to quantify the total amount of solid carbonate species and lithium acetylide $\left(\mathrm{Li}_{2} \mathrm{C}_{2}\right)$ within the solid electrolyte interphase (SEI). Finally, electrochemical modeling is combined with experimental data to determine the Li plating exchange current density $\left(10 \mathrm{~A} / \mathrm{m}^{2}\right)$ and stripping efficiency $(65 \%)$ of plated Li metal on graphite. These techniques provide a highly accurate measure of Li plating onset and quantitative insight into graphite SEI evolution during fast charge.
\end{abstract}




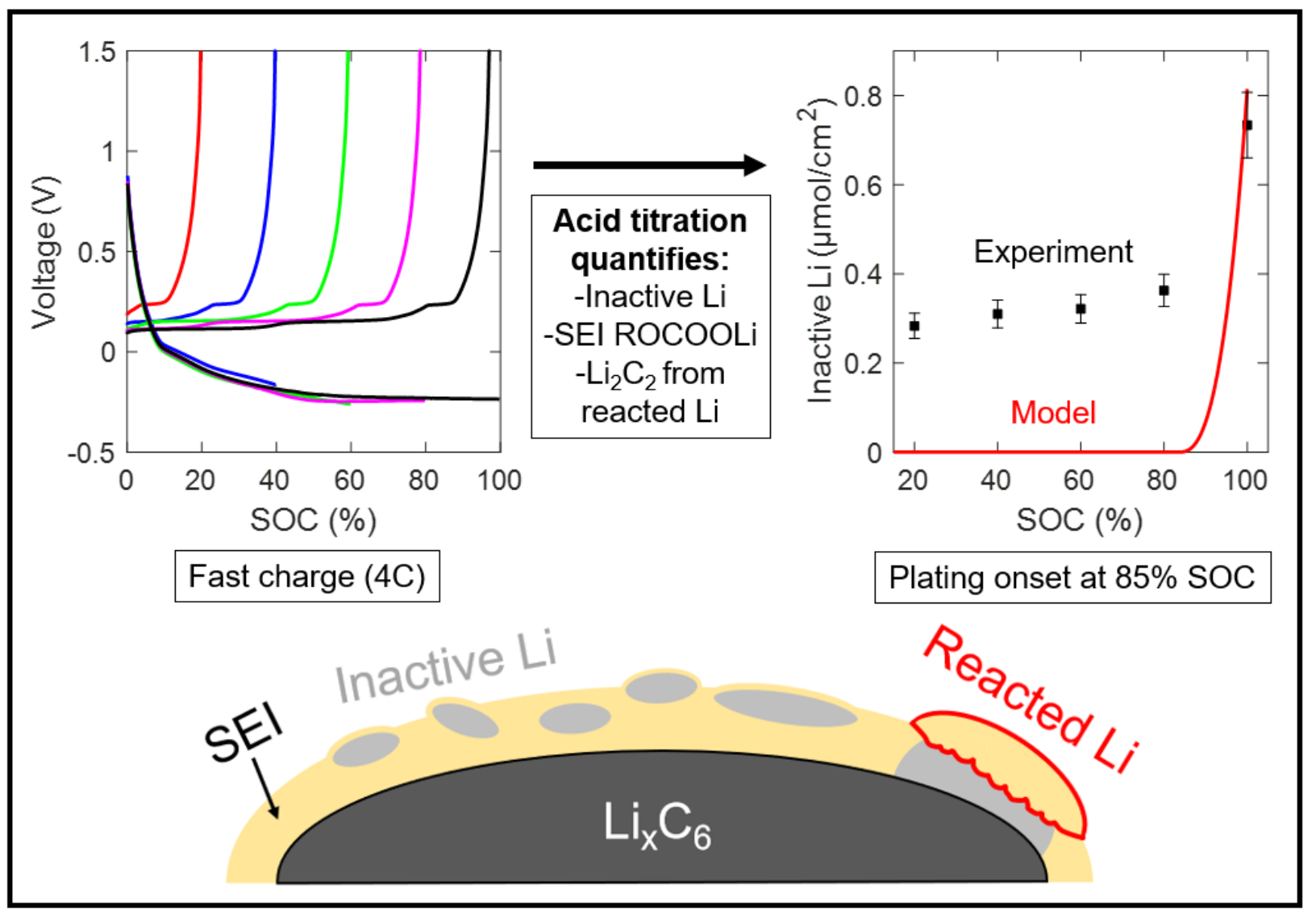

Table of Contents Figure

\section{Introduction}

The Department of Energy's stated goal for extreme fast charging (XFC) electric vehicle batteries is a 15-minute charge time that provides 300 miles of range, an approximate twofold improvement upon existing state-of-the-art batteries. ${ }^{1}$ However, several outstanding challenges must be addressed to bring such batteries to fruition. First, severe $\mathrm{Li}^{+}$concentration gradients necessarily manifest during fast charging, depleting the $\mathrm{Li}^{+}$concentration within the pores of the graphite electrode near the current collector, thereby limiting the capacity that can be attained for a given cutoff voltage. ${ }^{2,3,4}$ Additionally, high overpotentials required to drive the necessary current can lead to Li metal deposition on the graphite particle surface. ${ }^{5,6}$ This process, commonly referred to as $\mathrm{Li}$ plating, is problematic for two reasons: 1) Li is known to deposit as dendrites, which can propagate across the separator and short the cell, and 2) Li metal plating/stripping is notoriously irreversible, either due to the highly reactive nature of Li with the battery electrolyte or because a 
large portion of the plated $\mathrm{Li}$ is electronically isolated upon stripping. ${ }^{7,8,9,10}$ Thus, evaluating the onset and extent of Li plating is crucial for enabling XFC batteries.

Many have reported techniques that can detect Li plating during cycling - an important advance for enabling XFC - but few have been able to provide quantifiable information from the observed plating signals. Some of these methods for operando detection of Li plating on graphite include microscopy, ${ }^{11}$ neutron diffraction, ${ }^{12,13}$ calorimetry, ${ }^{14}$ and monitoring of electrochemical signatures during rest and discharge. ${ }^{15,16,17,18}$ All of the techniques come with unique challenges from a cell design, breadth of view, and sensitivity perspective, but the overarching challenge remains the lack of quantifiable information from the observed plating signal. It remains crucial to determine the amount of $\mathrm{Li}$ that has plated when a signal has been observed, particularly at the onset of plating where it is important to detect $\mathrm{Li}$ in the smallest amounts possible.

Lithium plating is difficult to detect and quantify for several reasons. Detection by inspection of voltage profiles is challenging because it occurs simultaneously with Li insertion into graphite during charging. Quantitative detection with other techniques is difficult because Li may undergo up to four additional processes upon deposition: 1) Li in contact with graphite can chemically insert into the graphite, 2) Li can become electronically isolated from graphite (either due to chemical insertion of the Li below it or physical dislodgement), 3) Li can be reversibly stripped off the graphite surface, and 4) Li can parasitically react with electrolyte. ${ }^{15,16,19}$ The second and forth processes would result in lost capacity, as the inventory of cyclable lithium would be decreased. Using our titration technique, we show herein that the predominant mechanism of capacity loss during initial fast charging is electronic isolation of $\mathrm{Li}$, and additional electrolyte degradation reactions become more important after prolonged cycling.

Much of the previous work on Li plating quantification has been limited to visual inspection of graphite electrodes post-mortem. Indeed, after cells have been cycled at moderate to fast ( 1C to 6C) charge rates for hundreds of cycles, a gray film of plated Li can be observed on the extracted graphite electrode. ${ }^{14,20,21}$ This insight is valuable to confirm that plated Li is a culprit in the resultant cell capacity loss but lacks quantitative information about the extent and onset of plating. To our knowledge, only one operando technique for quantification of plated Li on graphite at the electrode scale currently exists, and this involves a customized cylindrical electron paramagnetic resonance spectroscopy (EPR) cell with a copper wire current collector. ${ }^{22}$ This 
technique is remarkably sensitive $(\sim 300 \mathrm{nmol}$ Li precision $)$ and fairly rapid (2 minutes/measurement), but it remains important to extend these desirable traits to more conventional cell configurations. More recently, a titration gas chromatography (TGC) technique was developed for ex-situ quantification of inactive $\mathrm{Li}$ in Li metal batteries. ${ }^{7}$ In the TGC work, extracted $\mathrm{Cu}$ electrodes and separators from $\mathrm{Cu}-\mathrm{Li}$ cells were placed into an Ar-filled air-tight septum vessel and water was injected into the vessel, producing $\mathrm{H}_{2}$ gas from the reaction of water with residual inactive $\mathrm{Li}$. The headspace of the vessel was sampled with an air-tight syringe and injected into a GC for $\mathrm{H}_{2}$ quantification, with a reported sensitivity of $\sim 150 \mathrm{nmol} \mathrm{Li}{ }^{7}$

In this work, we demonstrate a mass spectrometry titration (MST) for inactive Li quantification on graphite with a detection limit of $20 \mathrm{nmol} \mathrm{Li}$, which corresponds to $0.5 \mu \mathrm{Ah}$ of total plated lithium. This technique is a modified version of a similar titration ${ }^{23,24}$ to quantify $\mathrm{Li}_{2} \mathrm{CO}_{3}$ on extracted $\mathrm{Li}-\mathrm{O}_{2}$ battery cathodes and was recently used to quantify surface $\mathrm{Li}_{2} \mathrm{CO}_{3}$ on Li-rich and Li-stoichiometric NMC cathodes. ${ }^{25}$ With the MST, we precisely identify: 1) the charge rate at which Li plating is observed if the electrode is charged to its nominal full capacity (corresponding to $372 \mathrm{mAh} / \mathrm{g}$ graphite), and 2) the state of charge at which Li plating commences at a $4 \mathrm{C}$ rate (full charge in 15 minutes). We also use an electrochemical model to determine the $\mathrm{Li}$ plating exchange current density and the efficiency of plated Li stripping during discharge.

\section{Methods}

A comprehensive description of the titration procedure can be found in the Supporting Information (SI) of Ref. 23, and example titration calculations can be found in the SI of this manuscript. Graphite electrodes $\left(2.18 \mathrm{mAh} / \mathrm{cm}^{2}, 91.83 \mathrm{wt} \%\right.$ Superior Graphite SLC1506T, 2 wt\% Timcal C45 carbon, 6 wt\% Kureha 9300 PVDF binder, 0.17 wt\% oxalic acid, $6.38 \mathrm{mg} / \mathrm{cm}^{2}, 37.4 \%$ porosity, $47 \mu \mathrm{m}$ coating thickness) were provided by the Cell Analysis, Modeling and Prototyping (CAMP) facility at Argonne National Laboratory. Electrodes were punched in $11 \mathrm{~mm}$ disks for the studies outlined in Figures 1, 2, and 3, and $12.5 \mathrm{~mm}$ disks were used for the prolonged cycling study in Figure 4. Cells were cycled on a Biologic VMP3 potentiostat at $30{ }^{\circ} \mathrm{C}$ in Li-graphite Swagelok cells (12.5 mm inner diameter) with 1.2 $\mathrm{M} \mathrm{LiPF}_{6}$ in ethylene carbonate/ethyl methyl carbonate (EC/EMC) (3:7 wt/wt) electrolyte and Whatman QMA glass fiber separator. After cycling (always ending the cycle with delithiation to $1.5 \mathrm{~V}$ ), the graphite electrodes were extracted from the cells and rinsed gently (except where otherwise noted) for one minute in $300 \mu \mathrm{L}$ of 
dimethyl carbonate three times to remove residual electrolyte, which was necessary to avoid $\mathrm{CO}_{2}$ evolution from residual ethylene carbonate upon titration. ${ }^{26,27} \mathrm{We}$ also examined the influence of rinsing on the amount of Li detected, as is discussed later. The electrodes were then dried in the glovebox antechamber and preserved in airtight vials in the glovebox prior to titration. To quantify the inactive $\mathrm{Li}$ on the extracted electrode, the sample was placed in a titration vessel with a septum port as described in Ref. 23 and attached to an in-line mass spectrometer (MS), all the while maintaining an air-free environment in the vessel. After attaching the vessel and acquiring a baseline on the MS, 3.5 M sulfuric acid was injected into the vessel, evolving $\mathrm{H}_{2}$ via Reactions 1 and 2 (from inactive $\mathrm{Li}$ metal and $\mathrm{Li}_{\mathrm{x}} \mathrm{C}_{6}$ that has become electronically isolated during the first few cycles), $\mathrm{CO}_{2}$ via Reactions 3, 4, and 5 (from carbonate-containing species in the SEI such as lithium ethylene mono-carbonate (LiEMC), lithium ethylene di-carbonate (LiEDC), or lithium carbonate), and acetylene $\left(\mathrm{C}_{2} \mathrm{H}_{2}\right)$ via Reaction 6 from lithium acetylide $\left(\mathrm{Li}_{2} \mathrm{C}_{2}\right){ }^{28,29,30}$ The headspace was regularly sampled at two minute intervals and sent to the MS until the $\mathrm{m} / \mathrm{z}=2$, $\mathrm{m} / \mathrm{z}=44$, and $\mathrm{m} / \mathrm{z}=26$ signals had fully attenuated, allowing us to quantify the total amount of $\mathrm{H}_{2}$, $\mathrm{CO}_{2}$, and $\mathrm{C}_{2} \mathrm{H}_{2}$, respectively, evolved. Measurement error from baseline correction of the titration gas evolution curves was estimated to be $\pm 10 \%$ of the measured total gas evolved for $\mathrm{H}_{2}$ and $\mathrm{CO}_{2}$ and $\pm 20 \%$ for $\mathrm{C}_{2} \mathrm{H}_{2}$ due to differences in calibration (see SI Section 1.1).

$$
\begin{gathered}
\text { Reaction 1: } \mathrm{Li}+\mathrm{H}_{2} \mathrm{O} \rightarrow \mathrm{LiOH}+{ }_{2}^{1} \mathrm{H}_{2} \\
\text { Reaction 2: } \mathrm{Li}_{\mathrm{x}} \mathrm{C}_{6}+\mathrm{xH}_{2} \mathrm{O} \rightarrow \mathrm{xLiOH}+\mathrm{C}_{6}+{ }_{2}^{\mathrm{x}} \mathrm{H}_{2} \\
\text { Reaction 3: } \mathrm{HOCH}_{2} \mathrm{CH}_{2} \mathrm{OCO}_{2} \mathrm{Li}(\mathrm{LiEMC})+\mathrm{H}^{+} \rightarrow\left(\mathrm{CH}_{2} \mathrm{OH}\right)_{2}+\mathrm{Li}^{+}+\mathrm{CO}_{2} \\
\text { Reaction 4: }\left(\mathrm{CH}_{2} \mathrm{OCO}_{2} \mathrm{Li}\right)_{2}(\mathrm{LiEDC})+2 \mathrm{H}^{+} \rightarrow\left(\mathrm{CH}_{2} \mathrm{OH}\right)_{2}+2 \mathrm{Li}^{+}+2 \mathrm{CO}_{2} \\
\text { Reaction 5: } \mathrm{Li}_{2} \mathrm{CO}_{3}+2 \mathrm{H}^{+} \rightarrow \mathrm{H}_{2} \mathrm{O}+2 \mathrm{Li}^{+}+\mathrm{CO}_{2} \\
\text { Reaction 6: } \mathrm{Li}_{2} \mathrm{C}_{2}+2 \mathrm{H}^{+} \rightarrow 2 \mathrm{Li}^{+}+\mathrm{C}_{2} \mathrm{H}_{2}
\end{gathered}
$$

To interpret results and predict lithium plating/stripping amounts during XFC, we employed a previously developed macro-homogeneous electrochemical half-cell model ${ }^{5,6,31}$ coupled with a lithium plating/stripping model which uses the framework proposed by Ren et al. ${ }^{32}$ The electrochemical properties of anodes using Superior 1506T graphite have been well- 
characterized and reported in previous work. ${ }^{5,6}$ Due to difficulties in the galvanostatic intermittent titration technique (GITT) for multi-phase materials, the solid-state diffusion coefficient and exchange current density were approximated from fitting to electrochemical data. Reported electrolyte transport properties for standard 1.2 $\mathrm{M} \mathrm{LiPF}_{6}$ in 3:7 by weight EC:EMC electrolyte were obtained from literature. ${ }^{31}$ Lastly, the lithium electrode was treated as an ideal electrode with the exchange current density set artificially high to prevent any significant overpotential at all charging rates. Relevant model parameters are summarized in Tables S1 and S2.

\section{Results and Discussion}

Each Li-graphite half-cell tested underwent two C/10 formation cycles with $0.010 \mathrm{~V}$ and $1.5 \mathrm{~V}$ cutoff potentials before fast charging, with the $\mathrm{C} / 10$ rate based on a $372 \mathrm{mAh} / \mathrm{g}$ graphite lithiation capacity. Here we refer to lithium insertion into graphite as "charging" and deinsertion as "discharging" despite the half-cell configuration. Figure 1a presents a typical cell cycling protocol: two formation cycles followed by three charge/discharge cycles with constant-current (CC) charge to $372 \mathrm{mAh} / \mathrm{g}$ and $\mathrm{CC}$ discharge to $1.5 \mathrm{~V}$. The charge rates were varied for different cells $(\mathrm{C} / 4, \mathrm{C} / 2,1 \mathrm{C}, 2 \mathrm{C}$, and $4 \mathrm{C})$ while the discharge rates remained constant $(\mathrm{C} / 4)$ for all cells. Similar results were obtained using slower discharge rates; for example, the same amount (within standard cell-to-cell variability) of inactive $\mathrm{Li}$ was measured using a C/4 and a C/10 discharge rate following a given charge rate, indicating that the $\mathrm{C} / 4$ discharge was sufficient to remove all reversible $\mathrm{Li}$ and $\mathrm{Li}_{\mathrm{x}} \mathrm{C}_{6}$ from the graphite (see Figure $\mathrm{S} 5$ in the $\mathrm{SI}$ ). The amount of inactive $\mathrm{Li}$ present after the final discharge to $1.5 \mathrm{~V}$, as well as the cumulative irreversible capacity as measured using the difference between charge and discharge capacity of all fast charging cycles (i.e., not including the irreversible capacity of the formation cycles), is presented in Figure 1b. Of note, the cells cycled at the lowest charge rate studied, C/4, show non-zero inactive Li $(\sim 100$ $\mathrm{nmol} / \mathrm{cm}^{2}$ ) as measured using our titration protocol. We do not attribute this to plated Li metal, as we do not expect $\mathrm{Li}$ plating at a slow $\mathrm{C} / 4$ charge rate, but rather to electronically isolated $\mathrm{Li}_{\mathrm{x}} \mathrm{C}_{6}$ that is inevitably present due to volumetric expansion and subsequent detachment of $\mathrm{Li}_{\mathrm{x}} \mathrm{C}_{6}$ during the first formation cycle. ${ }^{33}$ This is supported by a control experiment wherein we titrated an electrode after just two C/10 formation cycles and measured $150 \mathrm{nmol} / \mathrm{cm}^{2}$ inactive Li, statistically equivalent to the inactive Li present on the electrode that underwent both the formation cycles and $\mathrm{C} / 4$ cycles (Figure 1b). Along these lines, we can conclude from Figure 1b that plating commences 
between $\mathrm{C} / 2$ and $1 \mathrm{C}$, as the inactive Li measured for $\mathrm{C} / 4$ and $\mathrm{C} / 2$ are within error of $100 \mathrm{nmol} / \mathrm{cm}^{2}$ while the $1 \mathrm{C}$ case is clearly higher $\left(\sim 400 \mathrm{nmol} / \mathrm{cm}^{2}\right)$.

By comparison of the inactive $\mathrm{Li}$ measured via titration (red) and the total irreversible capacities (black) in Figure 1b, we can conclude that a substantial portion of the irreversible capacity at higher charge rates is in fact due to inactive $\mathrm{Li}$, as both the inactive $\mathrm{Li}$ capacities and cumulative irreversible capacities increase similarly with increasing charge rate. We define an offset capacity ( $\left.Q_{\text {offset }}\right)$ in Equation 1, which is the difference between the total irreversible capacity ( $\left.\mathrm{Q}_{\text {tot }}\right)$ from cycling (excluding formation cycles) and the equivalent capacity of inactive Li ( $\mathrm{Q}_{\mathrm{Li}}$ ) measured via titration, and we plot this for each C-rate in Figure 1c. The offset capacity is similar within error at a baseline value of $20-30 \mu \mathrm{Ah} / \mathrm{cm}^{2}$ for C-rates of $2 \mathrm{C}$ and below, with a slight increase at $4 \mathrm{C}$.

$$
\mathrm{Q}_{\text {offset }}=\mathrm{Q}_{\text {tot }}-\mathrm{Q}_{\mathrm{Li}}
$$

The baseline $\mathrm{Q}_{\text {offset }}$ observed at all C-rates could arise from a number of different phenomena, including electrode rinsing or the formation of additional SEI components. To understand the impact of rinsing, we titrated an unrinsed electrode that underwent the standard formation cycles followed by three $4 \mathrm{C}$ charge, $\mathrm{C} / 4$ discharge cycles. We found that $\mathrm{Q}_{\text {offset }}$ and the measured inactive $\mathrm{Li}$ were similar within error to those reported in Figures $1 \mathrm{a}$ and $1 \mathrm{~b}$ for the rinsed electrode counterparts (see Figure S3). Thus, dislodgement of inactive Li from rinsing is not a major contributor to the offset capacity after just three fast charge cycles (we will show later that rinsing does influence the titration results after more cycles). Another plausible explanation for the observed $Q_{\text {offset }}$ is further SEI formation beyond the two formation cycles. We must be careful when addressing "SEI formation" broadly because the species comprising the SEI on graphite are diverse, almost always including carbonates, $\mathrm{LiF}$, and $\mathrm{Li}_{2} \mathrm{O}$, but occasionally also reported to include trace amounts of oxalates, succinates, and alkoxides, although truly quantitative information remains elusive. ${ }^{34,35,36,37}$ From our $\mathrm{CO}_{2}$ titration results in Figure 1d, we see that the amount of carbonate-containing SEI remains within error of the amount measured after just formation cycling for all C-rates, indicating that either carbonates do not continue to form beyond the formation cycles or are only loosely attached to the surface such that they are removed during the rinsing procedure. As outlined in SI Section 2.2, the slight increase in $\mathrm{CO}_{2}$ evolution observed for the $4 \mathrm{C}$ case only amounts to $\sim 5 \mu \mathrm{Ah} / \mathrm{cm}^{2}$ equivalent capacity, which is not enough to explain 
the total increase in $\mathrm{Q}_{\text {offset }}$ at 4C. Finally, we discuss the possibility that $\mathrm{Q}_{\text {offset }}$ might result from plated Li reacting to form a new (likely non-carbonate) species. Multiple reports have indicated that $\mathrm{Li}_{2} \mathrm{C}_{2}$ is observed on plated $\mathrm{Li}$ metal when using a $\mathrm{LiPF} 6$ in EC/EMC electrolyte, and the $\mathrm{Li}_{2} \mathrm{C}_{2}$ hydrolyzes to form $\mathrm{C}_{2} \mathrm{H}_{2}$ gas upon exposure to water. ${ }^{29,30}$ In Figure 1e, we see that the amount of $\mathrm{Li}_{2} \mathrm{C}_{2}$ measured via titration grows with increasing $\mathrm{C}$-rate, indicating that $\mathrm{Li}_{2} \mathrm{C}_{2}$ formation is correlated with total $\mathrm{Li}$ plated (which also increases with increasing C-rate above $\mathrm{C} / 2$ ) and contributes to the increased $\mathrm{Q}_{\text {offset }}$ at $4 \mathrm{C}$. The $\mathrm{Li}_{2} \mathrm{C}_{2}$-forming reaction is likely chemical as opposed to electrochemical, as the amount of $\mathrm{Li}_{2} \mathrm{C}_{2}$ grows with increasing OCV time between charge and discharge (see Figure S6d), when plated Li is free to react chemically with electrolyte. With this in mind, we can calculate an equivalent capacity of $\mathrm{Li}_{2} \mathrm{C}_{2}$ (right y-axis in Figure 1e) due to a chemical reaction with plated $\mathrm{Li}$, and we see that again $\mathrm{Li}_{2} \mathrm{C}_{2}$ alone cannot account for the overall increase in $\mathrm{Q}_{\text {offset }}$ with increasing charge rate. Other species that are rinsed off, dissolve into the electrolyte, or cannot be measured with our titration must account for the remainder of the offset. In summary, a substantial portion of the irreversible capacity from fast charging can be attributed to inactive $\mathrm{Li}$, but further SEI formation beyond the formation cycles and reaction of plated $\mathrm{Li}$ with electrolyte also contribute, especially at higher charge rates. The baseline $Q_{\text {offset }}$ is due to formation of non-carbonate $\mathrm{SEI}$ species such as $\mathrm{LiF}$ or $\mathrm{Li}_{2} \mathrm{O}$ or "loose" carbonate species formed beyond the formation cycles (although we suspect "loose" carbonates are more likely, as LiF and $\mathrm{Li}_{2} \mathrm{O}$ are confined to the innermost portion of the SEI which is less accessible after formation), ${ }^{36}$ and the increase in offset capacity at higher C-rates is due to the reaction of plated Li with electrolyte to form other species such as $\mathrm{Li}_{2} \mathrm{C}_{2}$. 

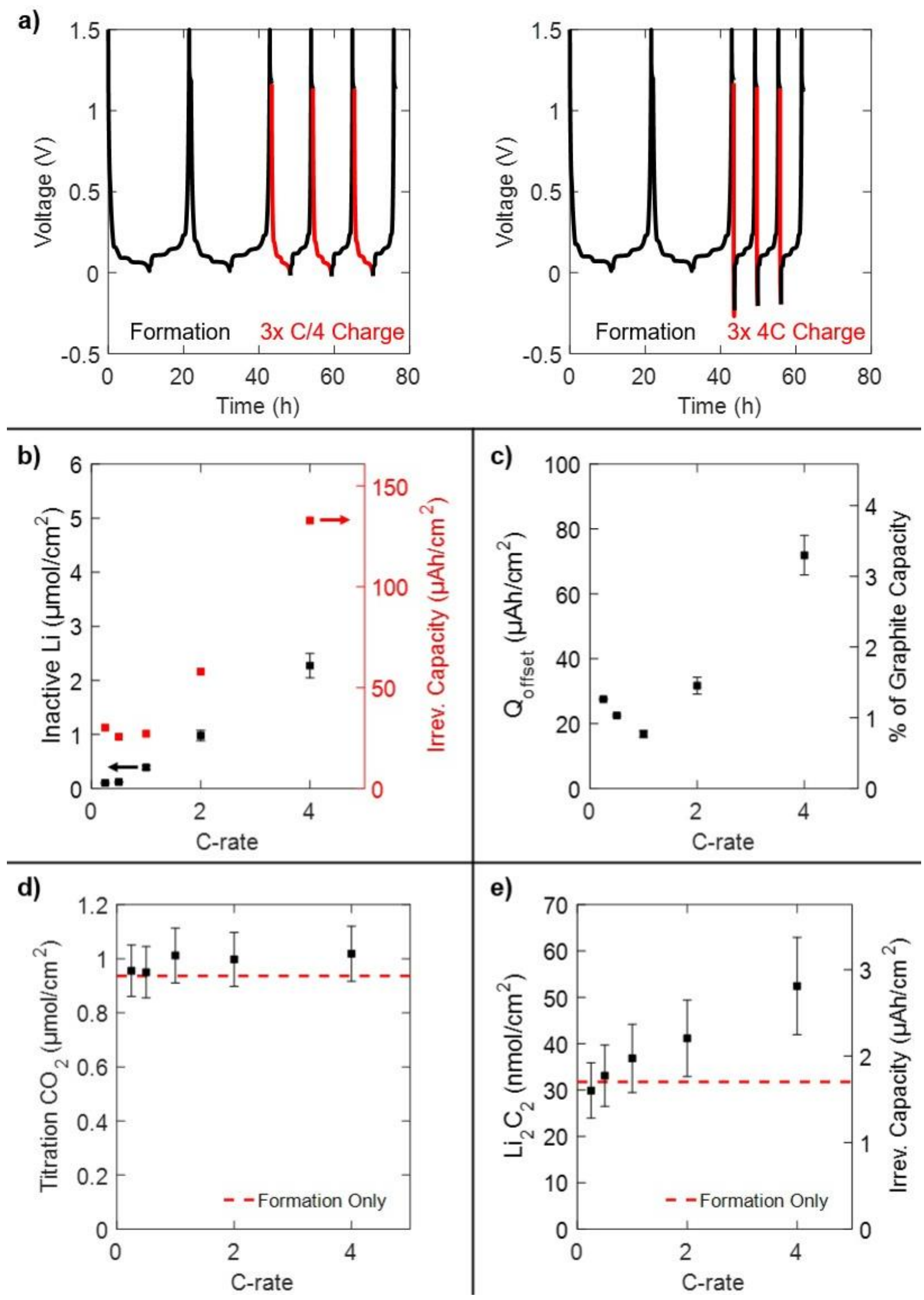
Figure 1. a) Examples of cell cycling procedure: two C/10 formation cycles (0.010-1.5 V) followed by three cycles of varying charge rate (shown in red) and $\mathrm{C} / 4$ discharge to $1.5 \mathrm{~V}$ with 30-minute OCV period between each charge/discharge. b) Inactive Li (black) measured via titration and cumulative irreversible capacity (red) of the three $\mathrm{CC}$ cycles after formation (obtained from cycling data) as a function of charge C-rate. Left and right y-axes are scaled such that the equivalent capacity of inactive Li can be read from the right y-axis (i.e. $1 \mu \mathrm{mol} \mathrm{Li} / 26.8 \mu \mathrm{Ah}$ ). Error bars indicate measurement error, which is $10 \%$ of the total measured inactive $\mathrm{Li}$ for $\mathrm{Li}$ titration results and $<1 \mu \mathrm{Ah}$ for irreversible capacities. c) Q Qffset (defined in Equation 1) as a function of C-rate. d) $\mathrm{CO}_{2}$ evolution upon titration as a function of $\mathrm{C}$-rate with error bars shown as $10 \%$ of the total measured $\mathrm{CO}_{2}$. Amount of titration $\mathrm{CO}_{2}$ measured on electrode that underwent only formation cycles overlaid as red dashed line for reference. e) $\mathrm{Li}_{2} \mathrm{C}_{2}$ measured via titration with error bars shown as $20 \%$ of the total measured $\mathrm{Li}_{2} \mathrm{C}_{2}$. Equivalent capacity of $\mathrm{Li}_{2} \mathrm{C}_{2}$ is shown on the right y-axis assuming $\mathrm{Li}_{2} \mathrm{C}_{2}$ is formed from a chemical reaction with plated $\mathrm{Li}$. Amount of $\mathrm{Li}_{2} \mathrm{C}_{2}$ measured on electrode that underwent only formation cycles overlaid as red dashed line for reference. All data points are averages from the results of two cells, and the full data set can be found in the SI.

It should be reiterated here that our technique is limited to quantifying inactive $\mathrm{Li}$ when the graphite electrode is in the fully discharged state. To obtain information about the expected amount of plated $\mathrm{Li}$ at other states during cycling, we combine our experimental data with electrochemical modeling as described in the Methods section. The model was first tested against cell cycling data to ensure fidelity between the experimental and model-predicted voltage profiles. From this fitting, we were also able to determine an appropriate exchange current density for the Li plating process, $i_{0, \mathrm{Li}}$. In Figure $2 \mathrm{a}$, we see that, while we experimentally observe a consistent decrease in voltage throughout the $4 \mathrm{C}$ charge, the model predicts a precipitous drop in the voltage near the end of the $4 \mathrm{C}$ charge for $\mathrm{i}_{0, \mathrm{Li}}$ less than $\sim 5 \mathrm{~A} / \mathrm{m}^{2}$, and the model more closely matches experimental data when $\mathrm{i}_{0, \mathrm{Li}}=10 \mathrm{~A} / \mathrm{m}^{2}$. Further, other $\mathrm{i}_{0, \mathrm{Li}}$ values reported in the literature are consistently at or near $\mathrm{i}_{0, \mathrm{Li}}=10 \mathrm{~A} / \mathrm{m}^{2} .{ }^{32,38}$ Thus, we use $\mathrm{i}_{0, \mathrm{Li}}$ of $10 \mathrm{~A} / \mathrm{m}^{2}$ for further analysis. The model inputs were designed to replicate the charging conditions in Figure 1 by simulating a single charge and multiplying the predicted amount of plated Li by three to simulate three chargedischarge cycles. We note that the amount of predicted inactive $\mathrm{Li}$ if all Li plates irreversibly (red line in Figure 2b) is around 3 times that measured at $4 \mathrm{C}$ in Figure 1b. This difference can be rationalized by assuming that a sizable fraction of lithium plated during fast charging is reversibly stripped during the $\mathrm{C} / 4$ discharge. Using a lithium stripping efficiency $\left(\alpha_{\text {str }}\right.$, defined as the percent of plated lithium that is stripped on subsequent discharge) of $65 \%$, which has been identified as a reasonable value in prior reports, ${ }^{22}$ our model with $\mathrm{i}_{0, \mathrm{Li}}=10 \mathrm{~A} / \mathrm{m}^{2}$ is in good agreement with the 
experimentally quantified amount of inactive Li (Figure 2b, green line). Modeling of lithium stripping is discussed in more detail in the SI.
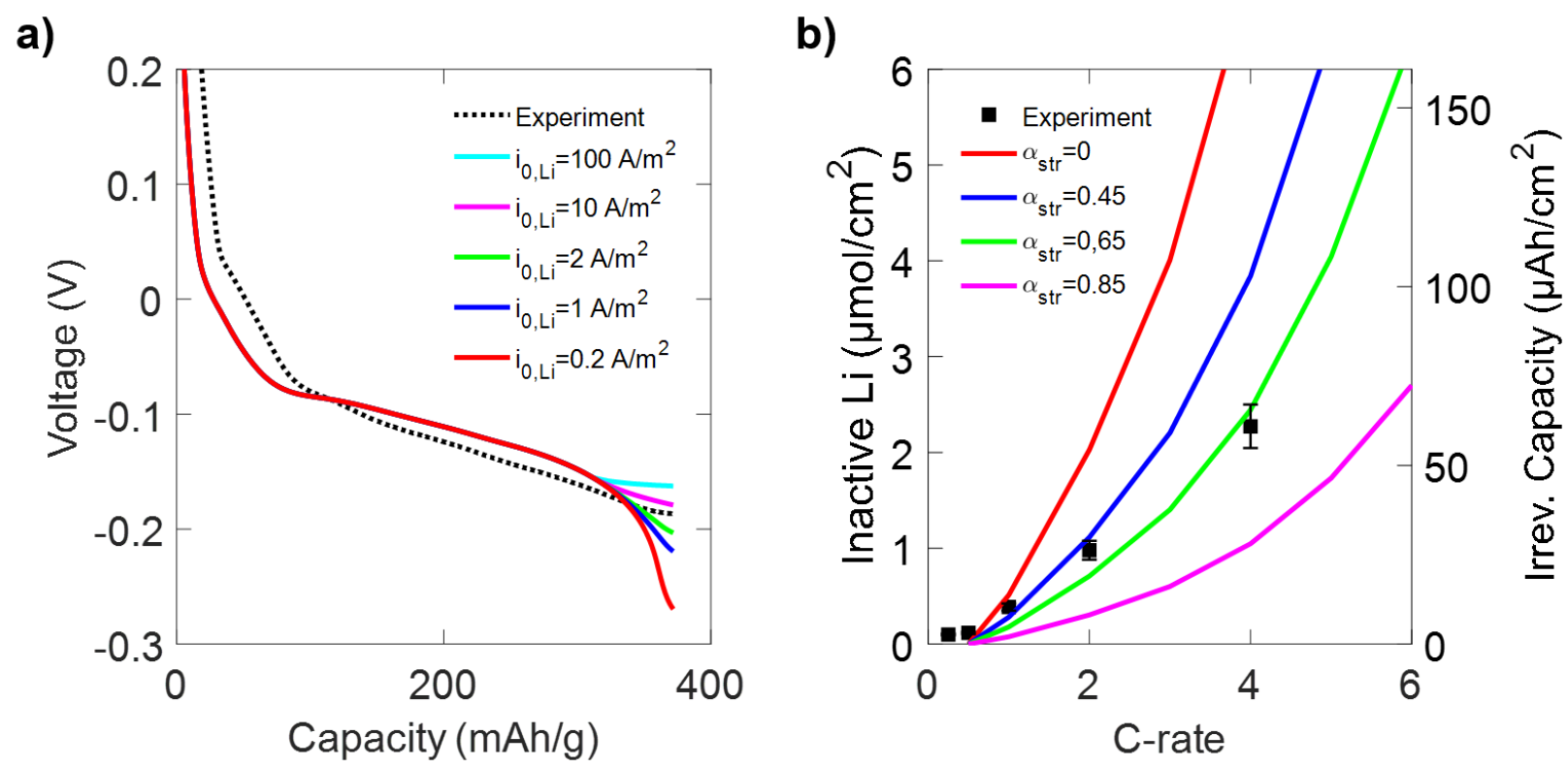

Figure 2. a) Experimentally measured $4 \mathrm{C}$ charge voltage profile (dotted line) overlaid with $4 \mathrm{C}$ charge modeling results (solid lines) of varying Li plating exchange current densities ( $\left.\mathrm{i}_{0, \mathrm{Li}}\right)$. b) Experimentally determined inactive Li (black squares) from Figure $1 \mathrm{~b}$ overlaid with model-determined inactive $\mathrm{Li}$ (solid lines) assuming various Li stripping efficiencies ( $\alpha_{\text {str }}$ ) using $\mathrm{i}_{0, \mathrm{Li}}=10 \mathrm{~A} / \mathrm{m}^{2}$. Modeling results were obtained by simulating a single $4 \mathrm{C}$ charge and multiplying the resultant inactive Li by three to simulate three $\mathrm{CC}$ charge-discharge cycles to directly compare to Figure 1 results.

With our ability to precisely quantify inactive $\mathrm{Li}$, we were also able to determine the onset of Li plating at the fastest tested $4 \mathrm{C}$ charge rate and compare this against the model. To do this, we cycled a different set of cells, each with two $\mathrm{C} / 10$ formation cycles as before followed by one 4C charge to varying capacities corresponding to $20 \%, 40 \%, 60 \%, 80 \%$, and $100 \%$ SOC (assuming $372 \mathrm{mAh} / \mathrm{g}$ capacity at $100 \% \mathrm{SOC}$ ) and a subsequent C/4 discharge to $1.5 \mathrm{~V}$. From Figure 3b, we see that inactive Li below $80 \%$ SOC remains reasonably constant and is likely due to electronically isolated $\mathrm{Li}_{\mathrm{x}} \mathrm{C}_{6}$. We conclude that plating occurs at $\sim 80-90 \% \mathrm{SOC}$, as there is a clear rise in the measured inactive Li above $80 \%$ SOC. This is in excellent agreement with the expected onset of Li plating based on the electrochemical model, as shown in Figure 3b. The model also predicts that Li plating commences at $99 \%$ SOC at $1 \mathrm{C}$ and at $96 \% \mathrm{SOC}$ at $2 \mathrm{C}$, both of which are reasonable values given the relative amounts of plated Li quantified in Figure 1b. As evidenced by Figures $3 \mathrm{c}$ and $3 \mathrm{~d}$, further carbonate-containing SEI formation and the reaction of plated $\mathrm{Li}$ to form $\mathrm{Li}_{2} \mathrm{C}_{2}$ do not influence our results, indicating that the relatively small amount of plated $\mathrm{Li}$ in this study is 
low enough to remain shielded from degradation by the already existing SEI from formation. We note here that plating occurs at a high SOC because the electrodes used in this study are thin compared to typical electric vehicle battery loadings. We would expect plating to occur at lower SOCs for thicker electrodes, and this will be a subject of future studies. Additionally, plating does not occur until the potential falls well below $0 \mathrm{~V}$ vs. Li due to the voltage loss across the thick separator. 
a)

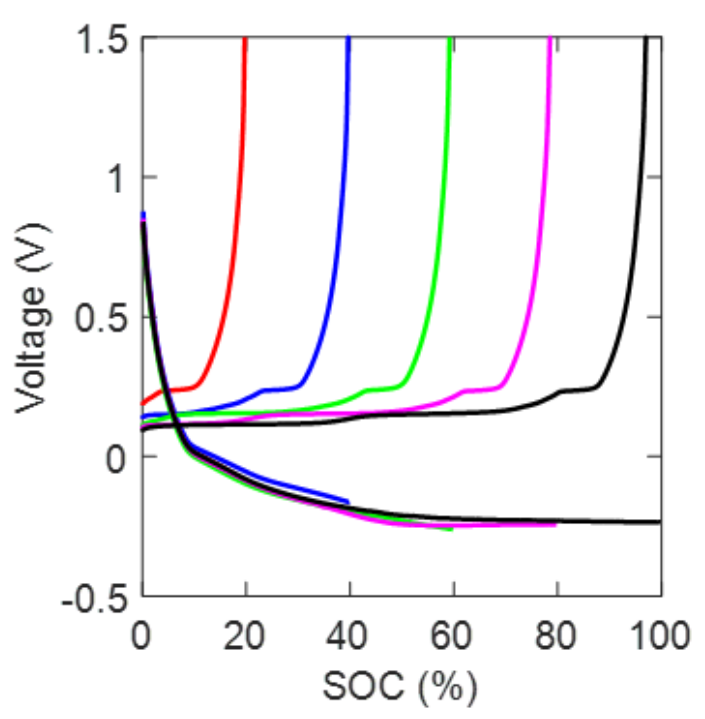

c)

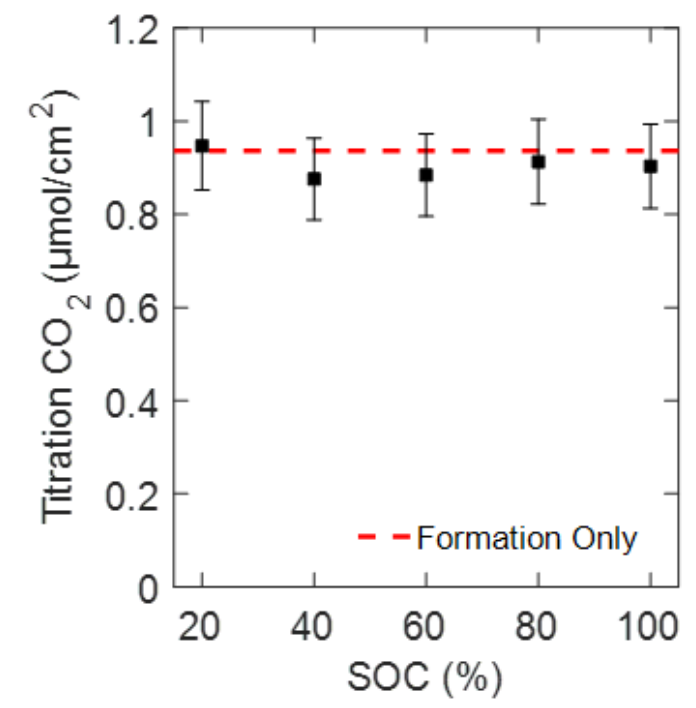

b)

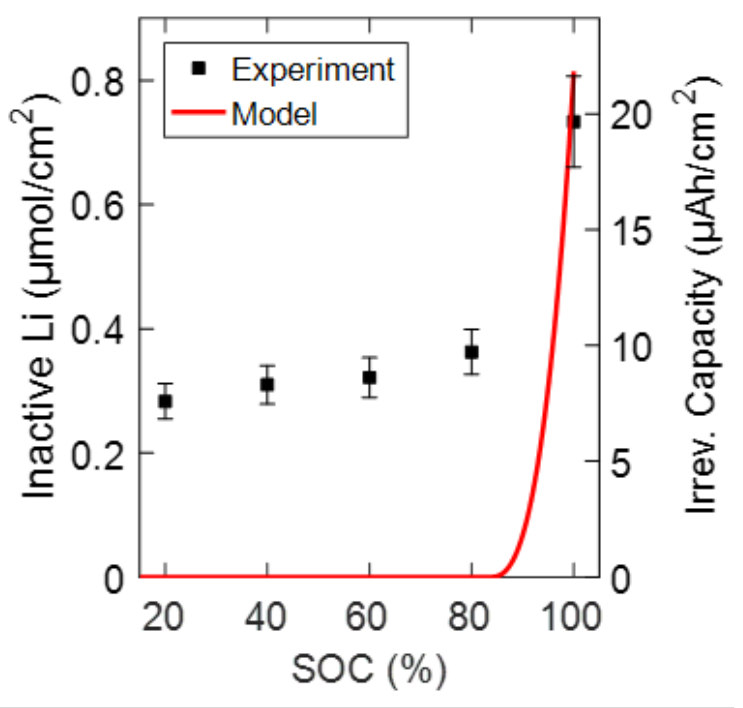

d)

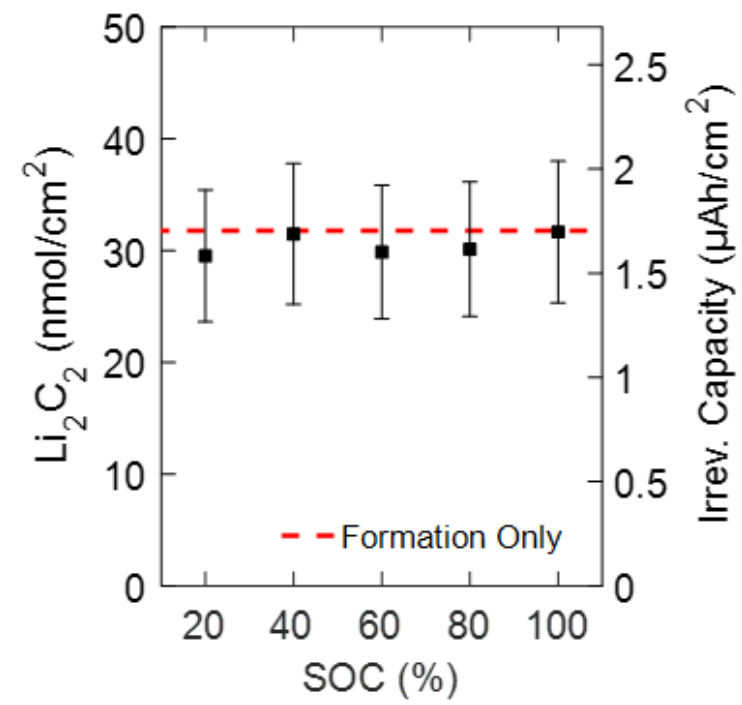

Figure 3. a) Overlaid voltage profiles of five cells charged to $20 \%, 40 \%, 60 \%, 80 \%$, and $100 \%$ SOC at $4 \mathrm{C}$ followed by $\mathrm{C} / 4$ discharge to $1.5 \mathrm{~V}$. Formation cycles are omitted for clarity. b) Inactive Li measured via titration for the five electrodes from panel a overlaid with model-predicted inactive $\mathrm{Li}$ for one simulated $4 \mathrm{C}$ charge assuming $65 \%$ reversible stripping of plated $\mathrm{Li}$. c) $\mathrm{CO}_{2}$ evolution upon titration as a function of $\mathrm{SOC}$ with reference $\mathrm{CO}_{2}$ evolution after just two formation cycles shown with red dashed line. d) $\mathrm{Li}_{2} \mathrm{C}_{2}$ measured via titration as a function of SOC with reference $\mathrm{Li}_{2} \mathrm{C}_{2}$ amount measured after just two formation cycles shown with red dashed line.

Comparing Figures $1 \mathrm{~b}$ and $3 \mathrm{~b}$, we notice that the amount of inactive $\mathrm{Li}$ after three $4 \mathrm{C}$ charge cycles $\left(\sim 2.1 \mu \mathrm{mol} / \mathrm{cm}^{2}\right)$ is about three times the amount after a single $4 \mathrm{C}$ cycle $(\sim 0.7$ $\mu \mathrm{mol} / \mathrm{cm}^{2}$ ). In Figure 4, we explore this trend further, now using electrodes of full $12.5 \mathrm{~mm}$ diameter to fill the interior of the cell and avoid degradation on the edges during prolonged cycling. 
We see in Figure 4a that the irreversible capacity continues to increase linearly with cycle number up to 10 cycles, which is consistent with the linear capacity decay typically observed over the first $\sim 30$ fast charge cycles in full pouch cells with similar graphite electrodes. ${ }^{39}$ However, the amount of inactive Li begins to taper off with increasing cycle number, resulting in increased $\mathrm{Q}_{\text {offset }}$ as shown in Figure 4b. A possible explanation for this behavior is that our post-cycling rinsing procedure (three brief rinses in DMC) removes some loosely bound Li that deposited during cycling. From the discussion related to Figure $1 \mathrm{~b}$ and Figure S3, we know that rinsing has minimal effect on the measured amount of inactive Li after three 4C charge cycles. Analyzing Figure 4a, however, we notice that rinsing begins to have a noticeable effect on the measured amount of inactive $\mathrm{Li}$ for five $4 \mathrm{C}$ charge cycles and above. The unrinsed electrode cycled 10 times, for example, had $\sim 4 \mu \mathrm{mol} / \mathrm{cm}^{2}$ more inactive Li compared to its unrinsed counterpart. Interestingly, we observe a clear rise in carbonate-containing species (see Figure 4c) after 5 and 10 cycles which coincides with the point which rinsing removes a portion of the plated $\mathrm{Li}$. We suspect that beyond 5 cycles, Li plates increasingly as mossy or dendritic Li which is more susceptible to being removed by rinsing procedures given that it is poorly adhered to the graphite surface. Furthermore, mossy Li has very high electrolyte-exposed Li surface area, which causes more electrolyte degradation, resulting in more solid carbonate deposition in the SEI (as shown in Figure 4c) and more $\mathrm{Li}_{2} \mathrm{C}_{2}$ formation (as shown in Figure $4 \mathrm{~d}$ ). 
a)

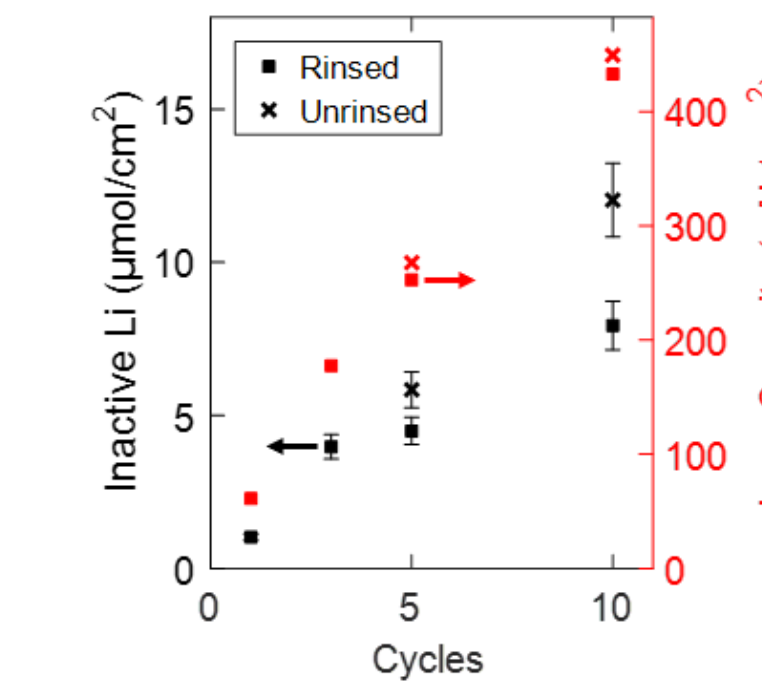

c)

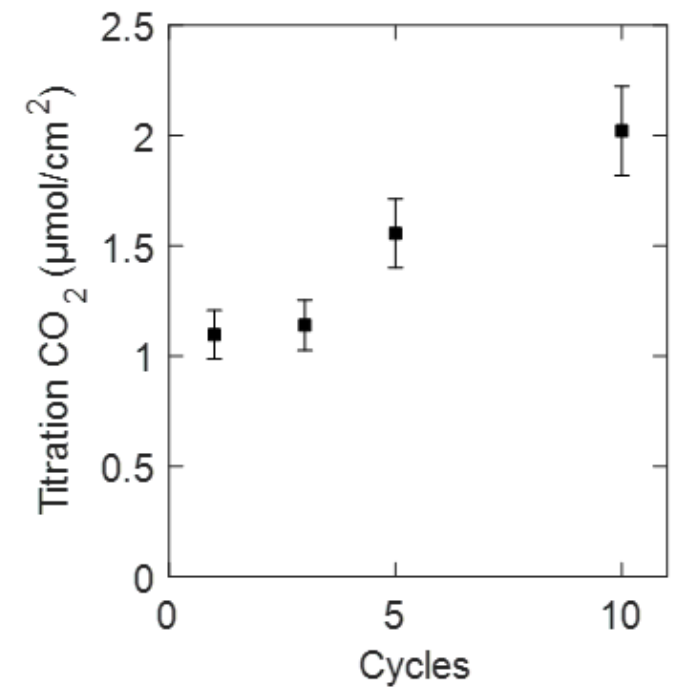

b)

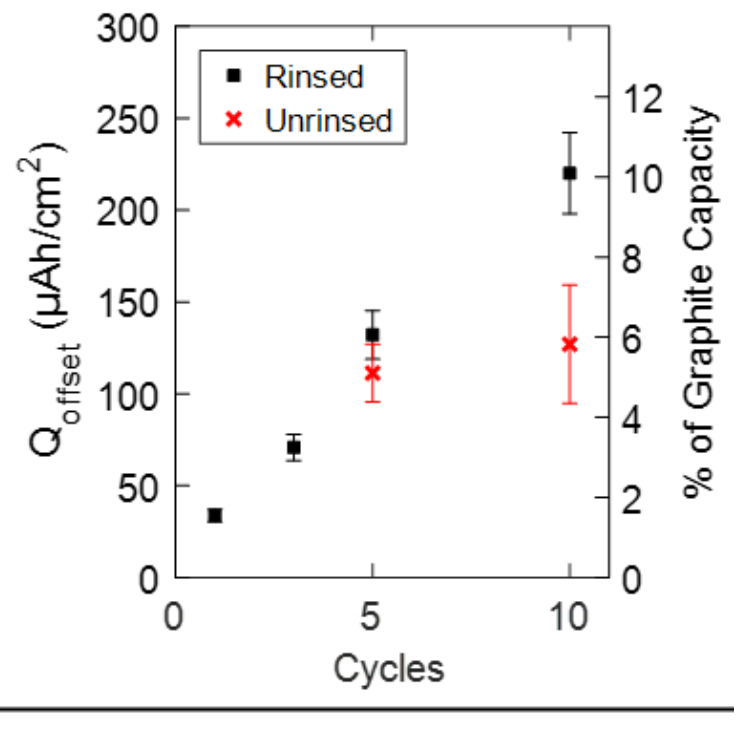

d)

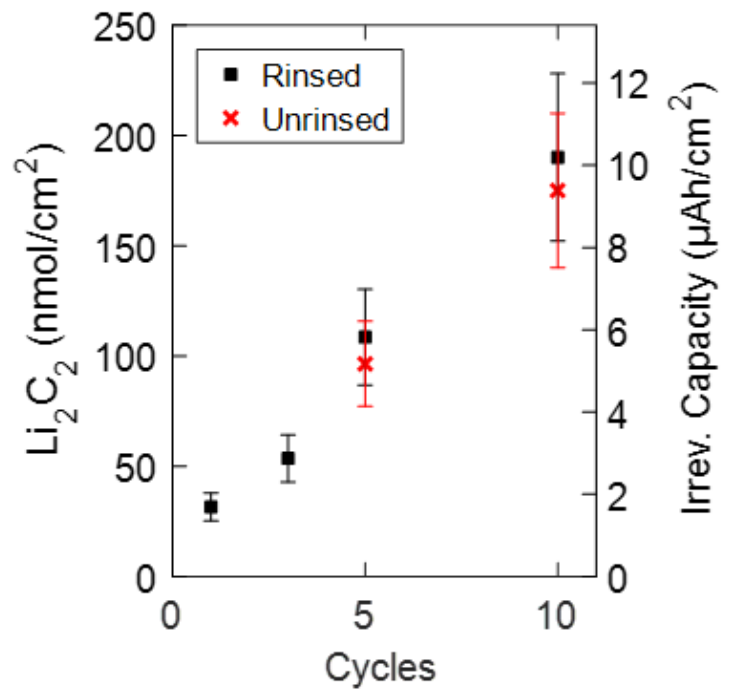

Figure 4. Acid titrations of $12.5 \mathrm{~mm}$ diameter electrodes cycled multiple times at $4 \mathrm{C}$ charge rate. a) Inactive $\mathrm{Li}$ (black) measured via titration and cumulative irreversible capacity after formation (red) for electrodes that have undergone varying numbers of $4 \mathrm{C}$ charge, $\mathrm{C} / 4$ discharge cycles. Rinsed extracted electrode samples are shown with square markers while unrinsed samples are shown with ' $x$ ' markers. b) Offset capacity (defined in Equation 1) as a function of cycle number for rinsed and unrinsed samples. c) $\mathrm{CO}_{2}$ evolution upon titration as a function of cycle number. d) $\mathrm{Li}_{2} \mathrm{C}_{2}$ amount as a function of cycle number.

\section{Conclusions}

In summary, we have developed a highly sensitive titration technique to quantify inactive $\mathrm{Li}$, carbonate-containing $\mathrm{SEI}$, and $\mathrm{Li}_{2} \mathrm{C}_{2}$ on cycled graphite electrodes. Using the titration technique, we: 1) identified the SOC at which plating occurred at a fast $4 \mathrm{C}$ charge rate, 2) 
determined the charge rate at which plating occurred if charged to full nominal capacity, and 3) quantified the contribution of inactive Li to the observed irreversible capacity during fast charging. By employing electrochemical modeling, we also determined the Li plating exchange current density and the stripping efficiency of plated Li on graphite. This study lays the groundwork for benchmarking the detection limit of Li plating detection techniques and provides an avenue to pursue more comprehensive studies of plating, stripping, and chemical insertion of Li on graphite surfaces.

\section{Acknowledgements}

This work was authored in part by the National Renewable Energy Laboratory, operated by Alliance for Sustainable Energy, LLC, for the U.S. Department of Energy (DOE) under Contract No. DE-AC36-08GO28308. Funding was provided by the U.S. DOE Office of Vehicle Technology Applied Battery Research and Extreme Fast Charge Program (XCEL). The views expressed in the article do not necessarily represent the views of the DOE or the U.S. Government. The U.S. Government and the publisher, by accepting the article for publication, acknowledges that the U.S. Government retains a nonexclusive, paid-up, irrevocable, worldwide license to publish or reproduce the published form of this work, or allow others to do so, for U.S. Government purposes. EJM and DEB acknowledge support from the National Science Foundation Graduate Research Fellowship under Grant No. DGE 1106400. We would also like to acknowledge the CAMP facility at Argonne National Laboratory, particularly Andy Jansen and Bryant Polzin, for providing the graphite electrodes used in this study. 


\section{References}

1. Howell, D. et al. Enabling Fast Charging: A Technology Gap Assessment. J. Power Sources 367, 250-262 (2017).

2. Diederichsen, K. M., McShane, E. J. \& McCloskey, B. D. Promising Routes to a High Li+ Transference Number Electrolyte for Lithium Ion Batteries. ACS Energy Lett. 2, 25632575 (2017).

3. Kim, D. H. et al. Toward Fast Operation of Lithium Batteries: Ion Activity as the Factor to Determine the Concentration Polarization. ACS Energy Lett. 4, 1265-1270 (2019).

4. Liu, Y., Zhu, Y. \& Cui, Y. Challenges and opportunities towards fast-charging battery materials. Nat. Energy 4, 540-550 (2019).

5. Colclasure, A. M. et al. Requirements for enabling extreme fast charging of high energy density Li-ion cells while avoiding lithium plating. J. Electrochem. Soc. 166, A1412A1424 (2019).

6. Colclasure, A. M. et al. Electrode scale and electrolyte transport effects on extreme fast charging of lithium-ion cells. Electrochim. Acta 337, (2020).

7. Fang, C. et al. Quantifying inactive lithium in lithium metal batteries. Nature 572, 511515 (2019).

8. Shu, Z. X., McMillan, R. S. \& Murray, J. J. Electrochemical Intercalation of Lithium into Graphite. J. Electrochem. Soc. 140, 922 (1993).

9. Lu, D. et al. Failure mechanism for fast-charged lithium metal batteries with liquid electrolytes. Adv. Energy Mater. 5, 1-7 (2015).

10. Boebinger, M. G., Lewis, J. A., Sandoval, S. E. \& McDowell, M. T. Understanding Transformations in Battery Materials Using in Situ and Operando Experiments: Progress and Outlook. ACS Energy Lett. 5, 335-345 (2020).

11. Shen, C. et al. Direct Observation of the Growth of Lithium Dendrites on Graphite Anodes by Operando EC-AFM. Small Methods 2, 1700298 (2018).

12. von Lüders, C. et al. Lithium plating in lithium-ion batteries investigated by voltage 
relaxation and in situ neutron diffraction. J. Power Sources 342, 17-23 (2017).

13. Zinth, V. et al. Lithium plating in lithium-ion batteries at sub-ambient temperatures investigated by in situ neutron diffraction. J. Power Sources 271, 152-159 (2014).

14. Downie, L. E. et al. In Situ Detection of Lithium Plating on Graphite Electrodes by Electrochemical Calorimetry. J. Electrochem. Soc. 160, A588-A594 (2013).

15. Petzl, M. \& Danzer, M. A. Nondestructive detection, characterization, and quantification of lithium plating in commercial lithium-ion batteries. J. Power Sources 254, 80-87 (2014).

16. Uhlmann, C., Illig, J., Ender, M., Schuster, R. \& Ivers-Tiffée, E. In situ detection of lithium metal plating on graphite in experimental cells. J. Power Sources 279, 428-438 (2015).

17. Waldmann, T., Hogg, B. \& Wohlfahrt-mehrens, M. Li plating as unwanted side reaction in commercial Li-ion cells - A review. J. Power Sources 384, 107-124 (2018).

18. Konz, Z. M., McShane, E. J. \& McCloskey, B. D. Voltage relaxation to detect the onset of lithium plating on graphite for fast charging. Submitted (2020).

19. Lee, J. Z. et al. Cryogenic Focused Ion Beam Characterization of Lithium Metal Anodes. ACS Energy Lett. 4, 489-493 (2019).

20. Yuan, Q. F. et al. Overcharge failure investigation of lithium-ion batteries. Electrochim. Acta 178, 682-688 (2015).

21. Petzl, M., Kasper, M. \& Danzer, M. A. Lithium plating in a commercial lithium-ion battery - A low-temperature aging study. J. Power Sources 275, 799-807 (2015).

22. Wandt, J., Jakes, P., Granwehr, J., Eichel, R. \& Gasteiger, H. A. Quantitative and timeresolved detection of lithium plating on graphite anodes in lithium ion batteries. Mater. Today 21, 231-240 (2018).

23. McCloskey, B. D. et al. Combining accurate $\mathrm{O}_{2}$ and $\mathrm{Li}_{2} \mathrm{O}_{2}$ assays to separate discharge and charge stability limitations in nonaqueous Li-O $\mathrm{O}_{2}$ Batteries. J. Phys. Chem. Lett. 4, 2989-2993 (2013). 
24. Ottakam Thotiyl, M. M., Freunberger, S. A., Peng, Z. \& Bruce, P. G. The carbon electrode in nonaqueous Li-O 2 cells. J. Am. Chem. Soc. 135, 494-500 (2013).

25. Renfrew, S. E. \& McCloskey, B. D. Residual Lithium Carbonate Predominantly Accounts for First Cycle $\mathrm{CO}_{2}$ and $\mathrm{CO}$ Outgassing of Li-Stoichiometric and Li-Rich Layered Transition-Metal Oxides. J. Am. Chem. Soc. 139, 17853-17860 (2017).

26. Metzger, M., Strehle, B., Solchenbach, S. \& Gasteiger, H. A. Hydrolysis of ethylene carbonate with water and hydroxide under battery operating conditions. J. Electrochem. Soc. 163, A1219-A1225 (2016).

27. Sloop, S. E., Kerr, J. B. \& Kinoshita, K. The role of Li-ion battery electrolyte reactivity in performance decline and self-discharge. Journal of Power Sources 119-121, 330-337 (2003).

28. Wang, L. et al. Identifying the components of the solid-electrolyte interphase in Li-ion batteries. Nat. Chem. 11, 789-796 (2019).

29. Schmitz, R. et al. SEI investigations on copper electrodes after lithium plating with Raman spectroscopy and mass spectrometry. J. Power Sources 233, 110-114 (2013).

30. Fonseca Rodrigues, M. T. et al. Lithium acetylide: A spectroscopic marker for lithium deposition during fast charging of Li-ion cells. ACS Appl. Energy Mater. 2, 873-881 (2019).

31. Usseglio-Viretta, F. L. E. et al. Resolving the discrepancy in tortuosity factor estimation for Li-ion battery electrodes through micro-macro modeling and experiment. $J$. Electrochem. Soc. 165, A3403-A3426 (2018).

32. Ren, D. et al. Investigation of lithium plating-stripping process in Li-ion batteries at low temperature using an electrochemical model. J. Electrochem. Soc. 165, A2167-A2167 (2018).

33. Tromans, D., Meech, J. A. \& Veiga, M. M. Natural organics and environmental stability of mercury: Electrochemical considerations. J. Electrochem. Soc. 143, 10-13 (1996).

34. An, S. J. et al. The state of understanding of the lithium-ion-battery graphite solid 
electrolyte interphase (SEI) and its relationship to formation cycling. Carbon N. Y. 105, 52-76 (2016).

35. Liu, T. et al. In situ quantification of interphasial chemistry in Li-ion battery. Nat. Nanotechnol. 14, 50-56 (2019).

36. Xu, K. Electrolytes and interphases in Li-ion batteries and beyond. Chem. Rev. 114, 11503-11618 (2014).

37. Augustsson, A. et al. Solid electrolyte interphase on graphite Li-ion battery anodes studied by soft X-ray spectroscopy. Phys. Chem. Chem. Phys. 6, 4185-4189 (2004).

38. Arora, P., Doyle, M. \& White, R. E. Mathematical modeling of the lithium deposition overcharge reaction in lithium-ion batteries using carbon-based negative electrodes. $J$. Electrochem. Soc. 146, 3543-3553 (1999).

39. Tanim, T. R., Shirk, M. G., Bewley, R. L., Dufek, E. J. \& Liaw, B. Y. Fast charge implications: Pack and cell analysis and comparison. J. Power Sources 381, 56-65 (2018). 


\section{Supporting Information for Quantification of Inactive Lithium and Solid Electrolyte Interphase (SEI) Species on Graphite Electrodes After Fast Charging}

Eric J. McShane ${ }^{1,2}$, Andrew M. Colclasure ${ }^{3}$, David E. Brown ${ }^{1,2}$, Zachary M. Konz ${ }^{1,2}$, Kandler Smith $^{3}$, and Bryan D. McCloskey ${ }^{1,2}$

1) Department of Chemical and Biomolecular Engineering, University of California, Berkeley, California 94720, United States

2) Energy Storage and Distributed Resources Division, Lawrence Berkeley National Laboratory, Berkeley, California 94720, United States

3) Transportation and Hydrogen Systems Center, National Renewable Energy Laboratory, Golden, Colorado 80401, United States

\section{Titration Calculations}

\subsection{Titration Data Analysis}

To determine the total amount of $\mathrm{H}_{2}, \mathrm{CO}_{2}$, and $\mathrm{C}_{2} \mathrm{H}_{2}$ evolved upon titration, $2 \mathrm{~mL}$ of the titration vessel headspace was sampled at 2-minute intervals. The gas was sent to a mass spectrometer which had been calibrated with various concentrations of $\mathrm{H}_{2}, \mathrm{CO}_{2}$, and $\mathrm{O}_{2}$ (in place of $\mathrm{C}_{2} \mathrm{H}_{2}$, introducing $\sim 20 \%$ error in quantification, as permanent gases besides $\mathrm{H}_{2}$ exhibit calibration slopes within $\sim 20 \%$ of one another) in Ar. Using the ratio between the $\mathrm{m} / \mathrm{z}=2$ signal (for $\mathrm{H}_{2}$ ) and $\mathrm{m} / \mathrm{z}=36$ signal (for Ar) along with our calibration line, we could calculate the mole fraction of $\mathrm{H}_{2}$ in each gas sample. The analogous process was done for $\mathrm{CO}_{2}$ (using $\mathrm{m} / \mathrm{z}=44$ instead of $\mathrm{m} / \mathrm{z}=2$ ) and $\mathrm{C}_{2} \mathrm{H}_{2}$ (using the $\mathrm{m} / \mathrm{z}=26$ signal with the $\mathrm{O}_{2}$ calibration slope). An example calibration line for $\mathrm{H}_{2}$ in $\mathrm{Ar}$ is shown in Figure $\mathrm{S} 1$. 


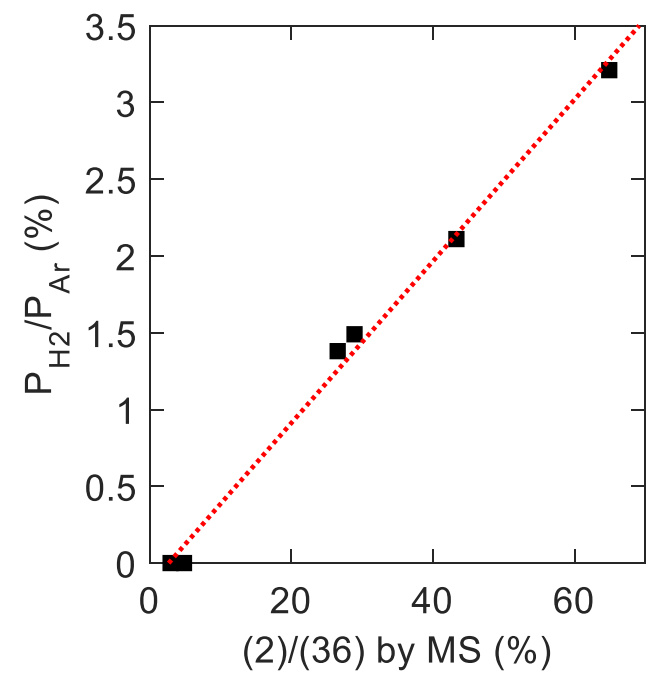

Figure S1. Calibration line used to quantify the mole ratio of $\mathrm{H}_{2}$ in an $\mathrm{Ar}$ carrier gas. Each point was obtained by supplying a gas of known $\mathrm{H}_{2}$ and Ar partial pressure (y-axis) to the MS, where the peak heights at $\mathrm{m} / \mathrm{z}$ ratios of 2 and 36 are recorded. The $\mathrm{r}^{2}$ for the calibration line is 0.994 .

We then used the Ideal Gas Law to calculate the total moles of $\mathrm{H}_{2}, \mathrm{CO}_{2}$, and $\mathrm{C}_{2} \mathrm{H}_{2}$ in each gas sample. Example $\mathrm{H}_{2}$ titration curves for the electrode samples in Figure 1 are overlaid in Figure S2. After allowing the signal to fully attenuate, we calculated the total gas evolved from the integration of each curve. Again, the analogous process was done for $\mathrm{CO}_{2}$ using the $\mathrm{m} / \mathrm{z}=44$ signal and $\mathrm{C}_{2} \mathrm{H}_{2}$ using the $\mathrm{m} / \mathrm{z}=26$ signal.

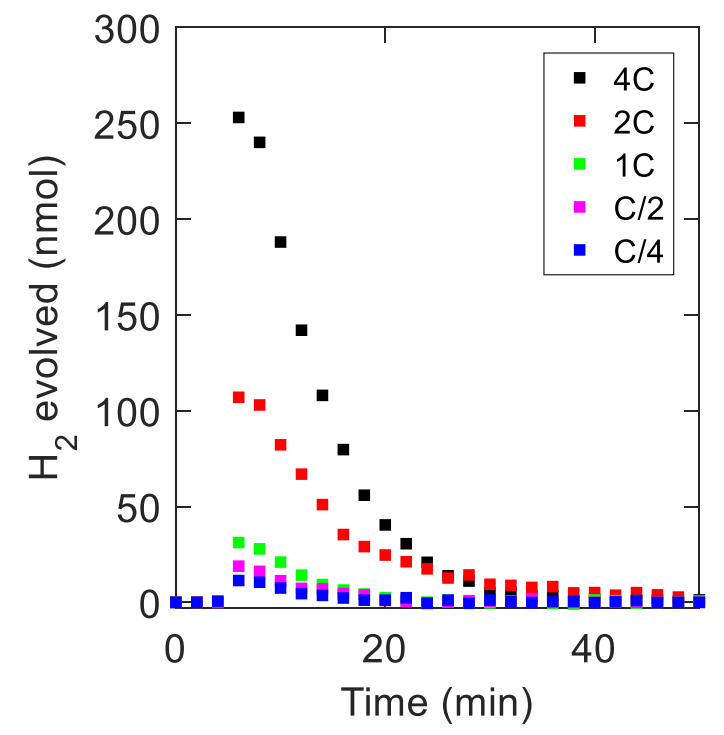

Figure S2. $\mathrm{H}_{2}$ gas evolution during titration for electrodes in Figure 1. Acid was injected before the fourth data point in each case. 


\section{Sources of Irreversible Capacity}

\subsection{Rinsing Effect on Inactive Li Measurement}

We see in Figure 1c that Qoffset (defined in Equation 1 in the main manuscript) is steady at a baseline value of $20-30 \mu \mathrm{Ah} / \mathrm{cm}^{2}$ for C-rates of $2 \mathrm{C}$ and below but increases slightly to $\sim 75 \mu \mathrm{Ah} / \mathrm{cm}^{2}$ for the 4C charge rate. One could propose that this increase in offset capacity is due to inactive Li being rinsed off the electrode surface prior to titration. To test this, we titrated an unrinsed electrode that had undergone the standard formation cycles followed by three cycles of $4 \mathrm{C}$ charge, $\mathrm{C} / 4$ discharge as in Figure 1. The results of the unrinsed electrode titration (Figure S3a) and the calculated offset capacity (Figure S3b) are shown overlaid upon data from Figures $1 \mathrm{~b}$ and 1c, respectively. We see that both the measured inactive $\mathrm{Li}$ and offset capacity are within error of the rinsed counterparts, indicating that rinsing does not have a significant effect on the measured inactive $\mathrm{Li}$ for three cycles and below of 4C charge, C/4 discharge. However, we see in Figure 4 that rinsing does have a significant impact for five or more cycles of $4 \mathrm{C}$ charge, $\mathrm{C} / 4$ discharge.

a)

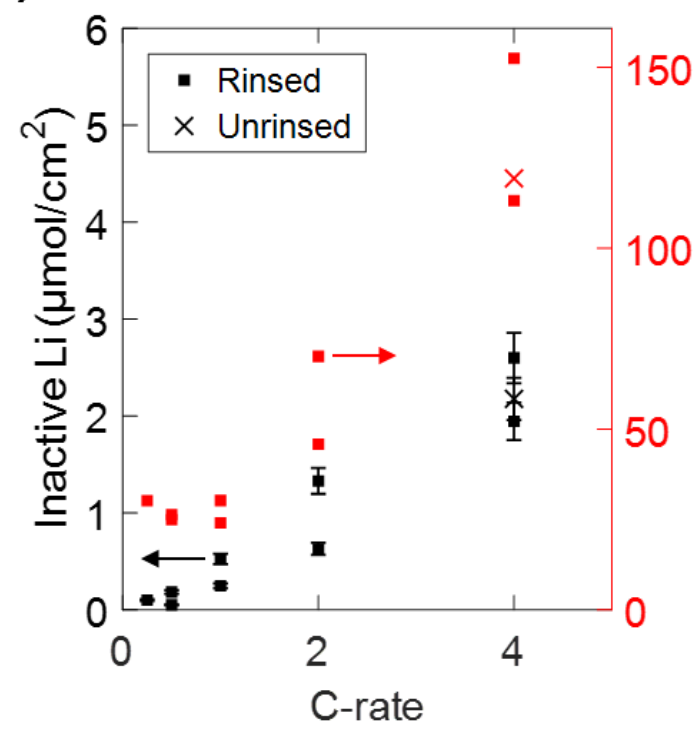

b)

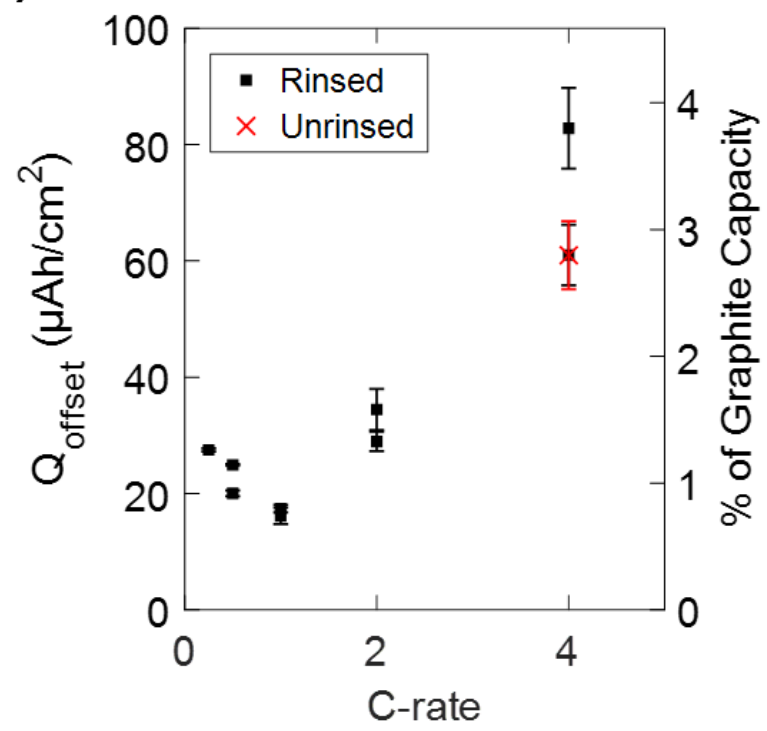

Figure S3. Unrinsed (' $x$ ' markers) titration results (black) and cumulative irreversible capacity (red) during CC cycling overlaid with data from Figures $1 \mathrm{~b}$ and $1 \mathrm{c}$.

\subsection{Correlation Between Titration $\mathrm{CO}_{2}$ and Irreversible Capacity}

In Figure 1d, we notice that the electrodes that underwent three $4 \mathrm{C}$ charge, $\mathrm{C} / 4$ discharge cycles after formation have $\sim 1 \mu \mathrm{mol} / \mathrm{cm}^{2} \mathrm{CO}_{2}$ evolved upon titration while the baseline electrode that 
only underwent two formation cycles evolved $\sim 0.9 \mu \mathrm{mol} / \mathrm{cm}^{2} \mathrm{CO}_{2}$, meaning there was a $\sim 100$ $\mathrm{nmol} / \mathrm{cm}^{2} \mathrm{CO}_{2}$ increase as a result of the three $\mathrm{CC}$ cycles after formation, although we note that $100 \mathrm{nmol} / \mathrm{cm}^{2}$ is just within the error of the measurement. Assuming this $\mathrm{CO}_{2}$ all comes from LiEMC, which was recently reported to be the most abundant species in the graphite SEI when using a similar electrolyte, ${ }^{1}$ we can convert the additional $\mathrm{CO}_{2}\left(\mathrm{n}_{\mathrm{CO} 2}\right)$ evolved after the three $\mathrm{CC}$ cycles to an equivalent irreversible capacity ( $\left.\mathrm{IC}_{\text {expected }}\right)$.

$$
\mathrm{IC}_{\text {expected }}=\mathrm{n}_{\mathrm{CO} 2} \frac{1 \text { mole LiEMC }}{1 \text { mole } \mathrm{CO}_{2}} \frac{2 \text { mole } \mathrm{e}^{-}}{1 \text { mole LiEMC }} \frac{96485 \mathrm{C}}{\text { mole } \mathrm{e}^{-}} \frac{\mathrm{mAh}}{3.6 \mathrm{C}}
$$

We assume two electrons are used to form one LiEMC, as recent reports propose LiEDC is formed first via a two-electron process, and this LiEDC chemically reacts to form LiEMC. ${ }^{1}$ Using 100 $\mathrm{nmol} / \mathrm{cm}^{2}$ for $\mathrm{n}_{\mathrm{CO} 2}$, we calculate $\mathrm{IC}_{\text {expected }} \sim 5 \mu \mathrm{Ah} / \mathrm{cm}^{2}$, which is not nearly enough to account for all of the offset capacity in Figure 1c. Thus, we suspect the offset capacity is due to a noncarbonate-containing SEI component (e.g., LiF) or the formation of electrolyte soluble solvent degradation products.

\subsection{Inactive Li in Separator}

Inactive Li that dislodges from the graphite electrode and ends up in the separator is another possible source of irreversible capacity that would not normally be accounted for by our titration technique. Since the counter electrode is Li metal, simply removing the separator from the cell and titrating it may yield inconsistent results because Li from the Li metal counter electrode could become entrained in the separator as well. To estimate the contribution of Li dislodged from the graphite and entrained in the separator, we made a cell with two Whatman QMA separators and titrated (without rinsing) both the graphite electrode and the separator adjacent to it (not the separator adjacent to the Li metal counter electrode). We tried this for a cell that underwent five 4C charge, $\mathrm{C} / 4$ discharge $\mathrm{CC}$ cycles after formation as well as ten $\mathrm{CC}$ cycles after formation. The ten-cycle electrode had substantial plating, such that the separator was adhered to the electrode, making analysis difficult. The five-cycle electrode titration results are plotted in Figure S3, which is overlaid with the data from Figure 4a. We note that, due to the thick double separator, the cumulative irreversible capacity during the five cycles is almost twice as large as the one separator, five cycle counterparts. We measure $\sim 9 \mu \mathrm{mol} / \mathrm{cm}^{2}$ inactive $\mathrm{Li}$ on the electrode alone and $\sim 2$ $\mu \mathrm{mol} / \mathrm{cm}^{2}$ inactive $\mathrm{Li}$ in the separator for a combined $\sim 11 \mu \mathrm{mol} / \mathrm{cm}^{2}$ inactive Li. This still does not 
account for all of the lost capacity during fast cycling, which would be $\sim 17 \mu \mathrm{mol} / \mathrm{cm}^{2}$ inactive $\mathrm{Li}$ equivalent. This shows that inactive Li dislodgement into the separator cannot be ignored when a large amount of Li has plated, but it is not at first estimation a major contributor to capacity loss.

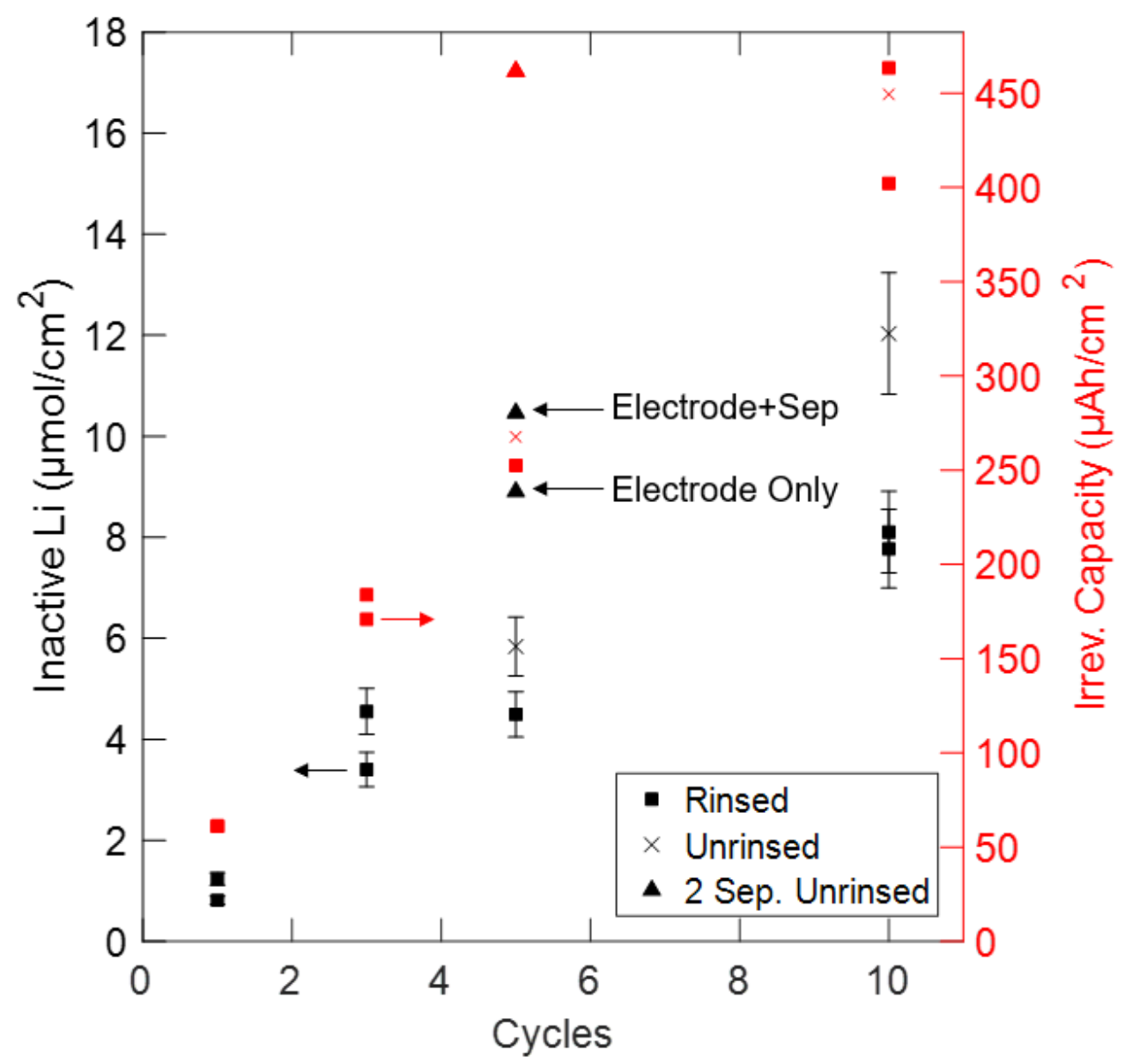

Figure S4. Two separator (triangles) titration results (black) and cumulative irreversible capacity (red) during 4C charge, $\mathrm{C} / 4$ discharge cycling overlaid with data from Figure 4a.

\subsection{Slower Discharge Rate}

Using a C/10 discharge instead of $\mathrm{C} / 4$ discharge after one $4 \mathrm{C}$ charge to $372 \mathrm{mAh} / \mathrm{g}$ yielded the same amount of inactive $\mathrm{Li}$ and titration $\mathrm{CO}_{2}$ within error. See Figure $\mathrm{S} 4$ below (which overlays Figures $3 \mathrm{~b}$ and $3 \mathrm{c}$, all containing $\mathrm{C} / 4$ discharge data) with the $\mathrm{C} / 10$ discharge result. This indicates that the $\mathrm{C} / 4$ discharge is a sufficiently slow rate to remove all reversible $\mathrm{Li}$ from the graphite. 

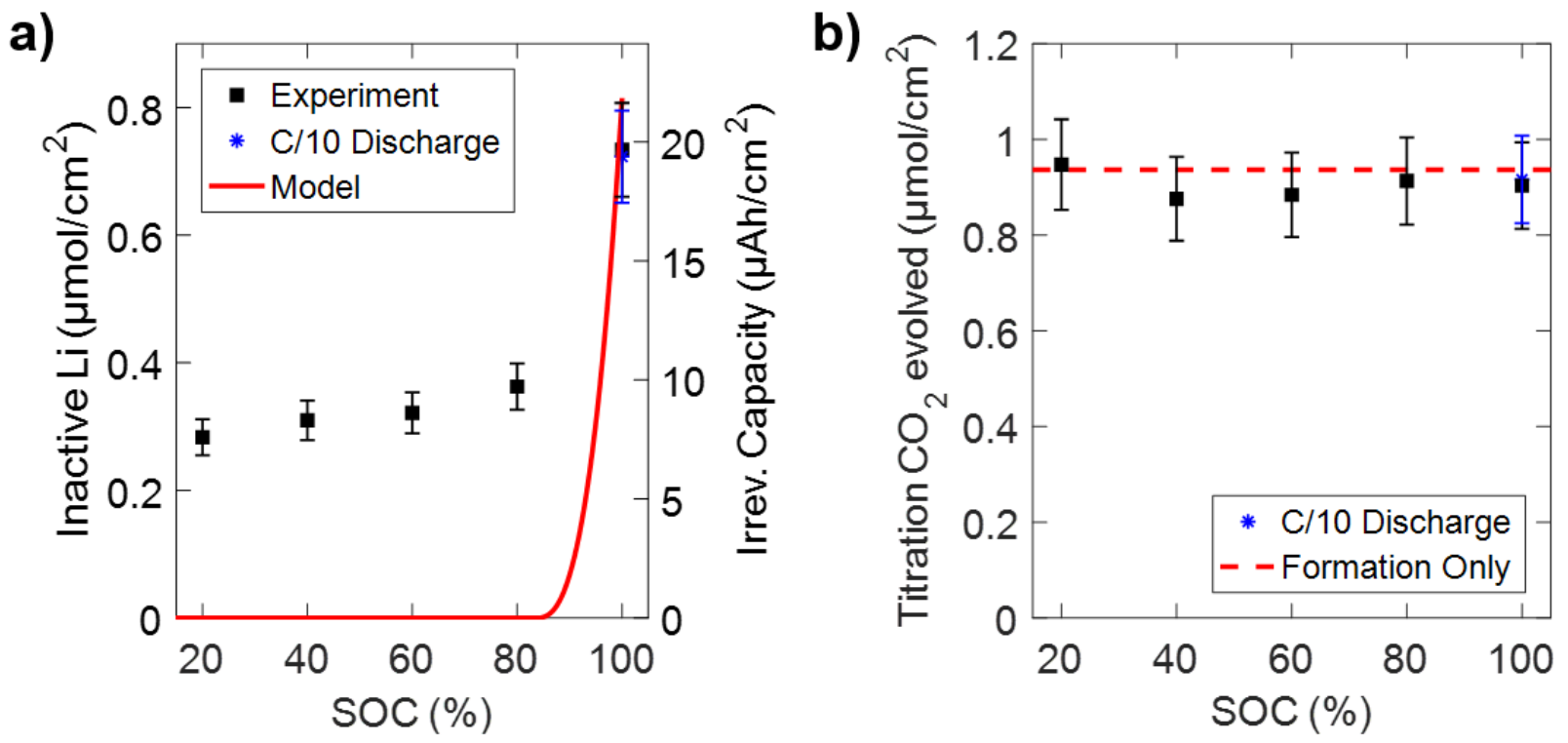

Figure S5. a) Inactive Li titration result for $\mathrm{C} / 10$ discharge case (*, blue) overlaid with Figure 3 b. b) Titration $\mathrm{CO}_{2}$ for $\mathrm{C} / 10$ discharge case $(*$, blue) overlaid with Figure $3 \mathrm{c}$.

\subsection{Effect of OCV Rest Period}

We also explored the impact of open circuit voltage (OCV) rest time between a 4C charge and C/4 discharge on the measured amount of inactive Li. Previous work ${ }^{2}$ suggests that a long OCV period (>15 minutes) would allow sufficient time for the plated $\mathrm{Li}$ in intimate contact with graphite to chemically insert into graphite that is not fully lithiated, leaving behind a layer of electronically isolated inactive Li. We hypothesized that by decreasing the OCV time, we could strip the plated Li before it had time to chemically insert, resulting in less inactive Li. However, we found that the effect of OCV time was only modest, with an average difference of only $\sim 0.5 \mu \mathrm{mol} / \mathrm{cm}^{2}$ inactive Li between the cells cycled with 0 and 30-minute OCV (Figure S6b), corresponding to an increase in stripping efficiency to $\sim 75 \%$ for the 0 -minute OCV case compared to $65 \%$ for the 30 -minute OCV case. The effect of decreased OCV time may be more pronounced when coupled with higher discharge rates, which would lower the possibility that plated Li continues to chemically insert into graphite during discharge, but we did not explore the effect of discharge rate in this work.

We also note that the amount of carbonate-containing SEI remains the same within error regardless of OCV time (Figure S6c), but the amount of $\mathrm{Li}_{2} \mathrm{C}_{2}$ increases with increasing OCV time (Figure $\mathrm{S} 6 \mathrm{~d})$. This implies that $\mathrm{Li}_{2} \mathrm{C}_{2}$ forms via a chemical reaction with plated $\mathrm{Li}$, as it is formed during the rest period when plated $\mathrm{Li}$ is present and no current is being passed. 
a)

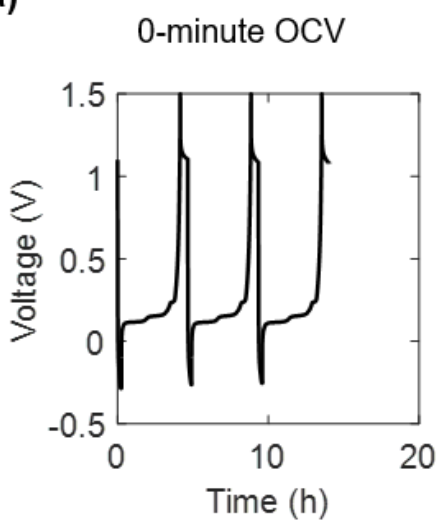

30-minute OCV

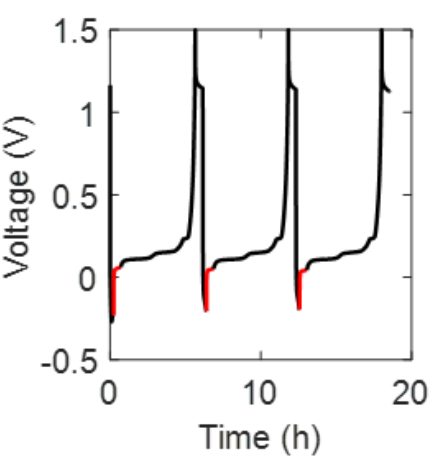

b)

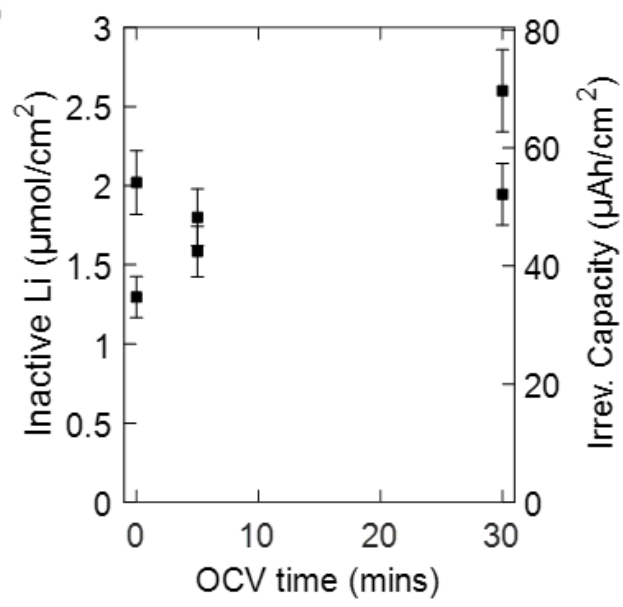

c)

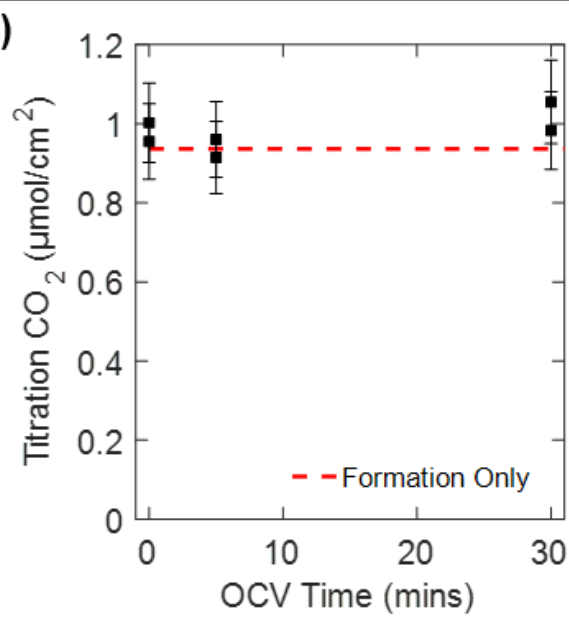

d)

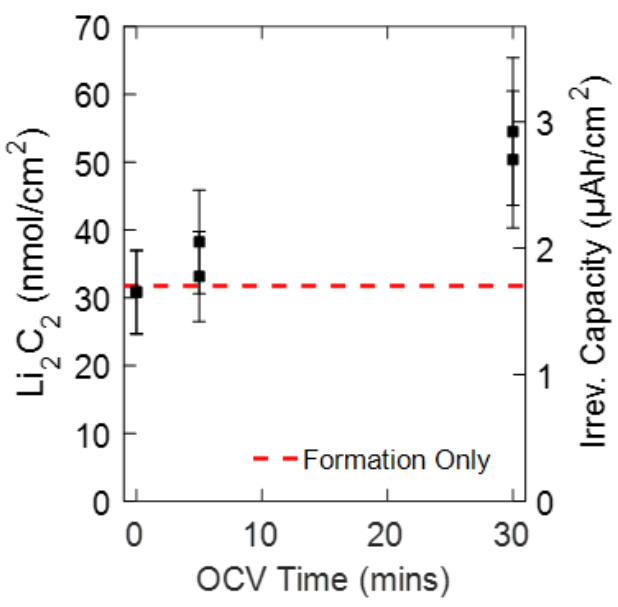

Figure S6. a) Examples of cell cycling procedure (two formation cycles not shown): three $4 \mathrm{C}$ charge, C/4 discharge cycles with 0-minute, 5-minute, and 30-minute OCV periods (shown in red) after each charge. OCV period after discharge remained at 30 minutes. b) Inactive Li measured via titration as a function of OCV time after charge. c) Titration $\mathrm{CO}_{2}$ as a function of $\mathrm{OCV}$ time between charge and discharge. d) $\mathrm{Li}_{2} \mathrm{C}_{2}$ measured via titration as a function of OCV time between charge and discharge.

\section{Modeling}

\subsection{Model Description}

A previously reported macro-homogeneous half-cell model is modified to consider lithium plating via the following reaction:

$\mathrm{Li}^{+}($electrolyte $)+\mathrm{e}^{-}($anode $) \Leftrightarrow \beta \mathrm{Li}^{\text {rev }}$ (anode $)+(1-\beta) \mathrm{Li}^{\text {irr }}$ (anode)

The text within the parentheses denotes the phase associated with the species. The lithium plating model builds upon the reaction framework proposed by Ren et al. ${ }^{3}$ The symbol $\beta$ represents the 
fraction of the lithium plating that can be reversibly stripped. For the proposed model, $\beta$ is assumed to be constant. The plating current associated with the above reaction is calculated with the following Butler-Volmer equation:

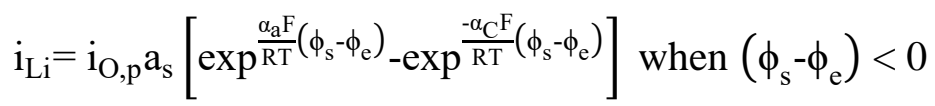

where $R, T$, and $F$ represent the universal gas constant, cell temperature, and Faraday's constant. Note, the convention used is that cathodic current (plating) is negative and anodic current (stripping) is positive. The specific surface area is calculated using the standard assumption of ideal disconnected spheres, $\mathrm{a}_{\mathrm{s}}=3 \varepsilon_{\mathrm{s}} / \mathrm{r}_{\mathrm{p}}$. The cathodic plating occurs when the solid phase potential $\phi_{\mathrm{S}}$ is below that of the surrounding electrolyte $\phi_{\mathrm{e}}$. An SEI film resistance was not considered in the model. The cathodic and anodic symmetry factors for lithium plating are taken to be $\alpha_{\mathrm{a}}=0.3$ and $\alpha_{C}=0.7 .^{4}$ The exchange current density for lithium plating $i_{O, p}$ is found by fitting to gas titration measurements for moles of plated lithium and electrochemical voltage signatures as seen in Figure 2. Anodic stripping is modeled with a similar Butler-Volmer equation modified, such that the rate of stripping goes to zero when all reversible lithium is consumed:

$\mathrm{i}_{\mathrm{Li}}=\mathrm{i}_{\mathrm{O}, \mathrm{s}} \mathrm{a}_{\mathrm{s}}\left[\exp ^{\frac{\alpha_{\mathrm{a}} \mathrm{F}}{\mathrm{RT}}\left(\phi_{\mathrm{s}}-\phi_{\mathrm{e}}\right)}-\exp ^{\frac{-\alpha_{\mathrm{C}} \mathrm{F}}{\mathrm{RT}}\left(\phi_{\mathrm{s}}-\phi_{\mathrm{e}}\right)}\right] \frac{\mathrm{C}_{\mathrm{Li}} \text { rev }}{\mathrm{C}_{\mathrm{Li}} \text { rev }+\gamma}$ when $\left(\phi_{\mathrm{s}}-\phi_{\mathrm{e}}\right)>0$

where $\gamma$ is set sufficiently low such that the above fraction goes to zero when the concentration of reversible plated lithium $\mathrm{C}_{\mathrm{Li}}$ rev is very low and 1 when for any significant concentration. A value of $\gamma=0.01$ is found to meet these criteria.

The change in concentration of reversible and irreversible plated lithium are calculated as follows when $\mathrm{i}_{\mathrm{Li}}<0$ and lithium is plating:

$\frac{\partial \mathrm{C}_{\mathrm{Li}}^{\mathrm{rev}}}{\partial \mathrm{t}}=-\beta \mathrm{i}_{\mathrm{Li}}$,

$\frac{\partial \mathrm{C}_{\mathrm{Li}} \mathrm{irr}}{\partial \mathrm{t}}=-(1-\beta) \mathrm{i}_{\mathrm{Li}}$

Conversely, when $\mathrm{i}_{\mathrm{Li}}>0$ and lithium is being stripped:

$\frac{\partial \mathrm{C}_{\mathrm{Li}} \text { rev }}{\partial \mathrm{t}}=-\mathrm{i}_{\mathrm{Li}}$, 
$\frac{\partial \mathrm{C}_{\mathrm{Li}} \mathrm{irr}}{\partial \mathrm{t}}=0$

The total number of moles of plated lithium is found by integrating the concentration across the anode thickness and multiplying by cell area:

$\mathrm{n}_{\mathrm{Li}}{ }_{\text {plated }}=\mathrm{A}_{\text {cell }} \int_{0}^{\mathrm{t}_{\mathrm{a}}}\left(\mathrm{C}_{\mathrm{Li}^{\text {rev }}}+\mathrm{C}_{\mathrm{Li}}{ }^{\text {irr }}\right) \mathrm{dz}$.

The typical conservation equations for solid phase potential, electrolyte potential, and electrolyte concentration are modified to consider Faradaic current from both intercalation chemistry and lithium plating/stripping. Lithium-ion fluxes from local changes in transference number are considered in the model. The model assumes isothermal operation due to the small cell area and relatively large thermal mass of Swagelok cell. The effect of deposited lithium on intercalation kinetics is neglected, but will be the subject of investigation moving forward.

\subsection{Model Parameters}

The half-cell model uses electrochemical parameters determined for graphite anodes composed of Superior Graphite 1506T active particles. Model inputs for electrolyte transport are taken from previously reported "Gen 2" electrolyte properties at $30{ }^{\circ} \mathrm{C} .{ }^{5}$ Table S1 and S2 summarize model inputs. The porosity of compressed Whatman glass separator is based on measuring a compressed thickness, weight of separator, and assuming a density of $2.25 \mathrm{~g} / \mathrm{cc}$ for borosilicate. The modeled cell area $0.96 \mathrm{~cm}^{2}$ is slightly larger than that of the coin cell punch $0.95 \mathrm{~cm}^{2}$ to match experimental results that measurable amounts of lithium plating occur only at rates above $\mathrm{C} / 2$. The Bruggeman exponent for graphite is based on measuring the tortuosity of $1506 \mathrm{~T}$ graphite electrodes via microstructure reconstruction and fitting to electrochemical rate data. ${ }^{6}$ 
Table S1. Electrochemical model parameter inputs for half-cell model. Concentrations for electrolyte $\mathrm{C}_{\mathrm{e}}$ and intercalated lithium $\mathrm{C}_{\mathrm{s}}$ are evaluated in $\mathrm{kmolm}^{-3}$.

\begin{tabular}{|l|l|l|l|}
\hline & Graphite Electrode & Separator & Lithium \\
\hline Thickness $(\mu \mathrm{m})$ & 47 & 200 & N/A \\
\hline Porosity $(\%)$ & 37.4 & 70 & N/A \\
\hline Particle Radius, $\mathrm{r}_{\mathrm{p}}(\mu \mathrm{m})$ & 4 & N/A & N/A \\
\hline Bruggeman Exponent & 2.1 & 1.5 & N/A \\
\hline $\begin{array}{l}\text { Exchange current density, } \mathrm{i}_{0} \\
\left(\text { A } \mathrm{m}^{-2}\right)\end{array}$ & $0.4\left(\mathrm{C}_{\mathrm{e}}\right)^{0.5}\left(\mathrm{C}_{\mathrm{s}}\right)^{0.5}\left(\mathrm{C}_{\mathrm{s}}-\mathrm{C}_{\mathrm{s}}^{\max }\right)^{0.5}$ & N/A & 100 \\
\hline $\begin{array}{l}\text { Solid-state Diffusion } \\
\text { Coefficient, } \mathrm{D}_{\mathrm{s}}\left(\mathrm{m}^{2} \cdot \mathrm{s}^{-1}\right)\end{array}$ & $3 \mathrm{E}-14$ & N/A & N/A \\
\hline $\begin{array}{l}\text { Maximum Intercalated } \\
\text { Lithium Concentration, } \mathrm{C}_{\mathrm{s}}^{\max } \\
\left(\mathrm{kmol}^{-3}\right)\end{array}$ & 31.0 & N/A & N/A \\
\hline
\end{tabular}


Table S2. Electrolyte transport properties for Gen2 electrolyte at $30{ }^{\circ} \mathrm{C} .{ }^{5}$ Concentrations for electrolyte $\mathrm{C}_{\mathrm{e}}$ are evaluated in $\mathrm{kmol} \mathrm{m}^{-3}$.

\begin{tabular}{|l|c|}
\hline Electrolyte Property & Expression \\
\hline Ionic conductivity, $\kappa(\mathrm{S} / \mathrm{m})$ & $\frac{\mathrm{C}_{\mathrm{e}}}{10}\left(4.9464-1.8143 \mathrm{C}_{\mathrm{e}}+0.07968 \mathrm{C}_{\mathrm{e}}^{2}+0.01947 \mathrm{C}_{\mathrm{e}}^{3}\right)^{2}$ \\
\hline $\begin{array}{l}\text { Diffusion Coefficient, } \mathrm{D}_{\mathrm{s}} \\
\left(\mathrm{m}^{2} \cdot \mathrm{s}^{-1}\right)\end{array}$ & $0.0001 \times 10^{\left(-4.8321-\frac{21.063}{\mathrm{~T}-62.147-12.195 \mathrm{C}_{\mathrm{e}}}-0.3852 * \mathrm{C}_{\mathrm{e}}\right)}$ \\
\hline Transference Number, $\mathrm{t}_{\mathrm{Li}^{+}}^{\mathrm{o}}$ & $-0.002395 \mathrm{C}_{\mathrm{e}}^{4}+0.024476 \mathrm{C}_{\mathrm{e}}^{3}-0.077134 \mathrm{C}_{\mathrm{e}}^{2}+0.074373 \mathrm{C}_{\mathrm{e}}+0.43031$ \\
\hline $\begin{array}{l}\text { Activity Coefficient, } \\
1+\frac{\mathrm{d} \ln \mathrm{f}_{ \pm}}{\mathrm{d} \ln \mathrm{C}_{\mathrm{e}}}\end{array}$ & $0.5556+1.85997 \mathrm{C}_{\mathrm{e}}-0.4917 \mathrm{C}_{\mathrm{e}}^{2}+1.0474 \mathrm{C}_{\mathrm{e}}^{3}-0.1376 \mathrm{C}_{\mathrm{e}}^{4}$ \\
\hline
\end{tabular}

\subsection{Model Results}

Figure S7 illustrates model results for half-cell voltage during a cycle with 4C lithiation. The entire cycle consists of a 900 second $4 \mathrm{C}$ lithiation, 30-minute rest, and C/4 delithiation. The model predicted voltage matches relatively well with that experimentally measured, but there are some slight discrepancies related to representing graphite as an intercalation material instead of a multiphase material, constant solid-state Li diffusion coefficient, and treating lithium electrode as ideal. Lithium plating is predicted to occur at $765 \mathrm{~s}$ into $4 \mathrm{C}$ charge corresponding to an average intercalation fraction of 0.85 (as seen in Figure 3b). Plating is not predicted until the cell voltage is $-155 \mathrm{mV}$ due to voltage loss at lithium electrode and across thick separator. The reported lithium plating model will be refined in future work to incorporate geometric effects such as inactive $\mathrm{Li}$ buildup, SEI growth, and varying stripping efficiencies depending on amount of plated Li and rest time. 


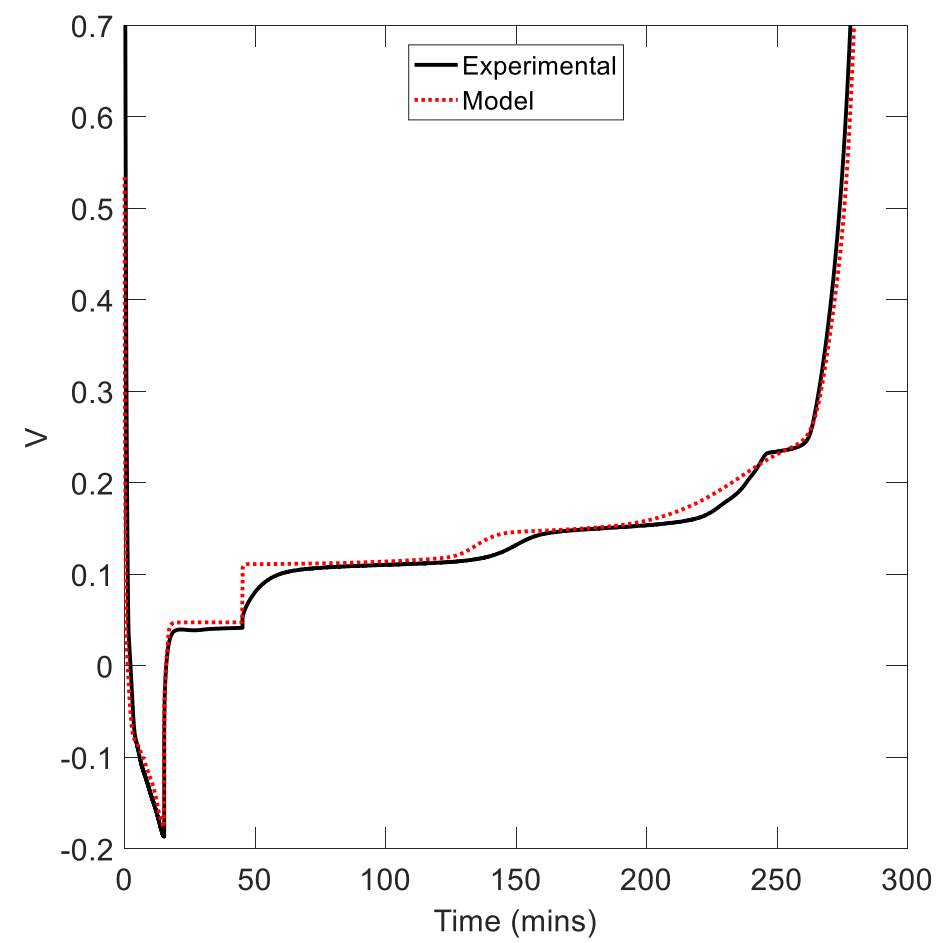

Figure S7. Comparison of model predicted voltage and measured voltage for lithium-graphite half-cell during $4 \mathrm{C}$ lithiation, 30-minute rest, and $\mathrm{C} / 4$ delithiation. The plating current density was set to $10 \mathrm{~A} / \mathrm{m}^{2}$ and the stripping efficiency was set to $65 \%$. 


\section{References}

1. Wang, L. et al. Identifying the components of the solid-electrolyte interphase in Li-ion batteries. Nat. Chem. 11, 789-796 (2019).

2. Uhlmann, C., Illig, J., Ender, M., Schuster, R. \& Ivers-Tiffée, E. In situ detection of lithium metal plating on graphite in experimental cells. J. Power Sources 279, 428-438 (2015).

3. Ren, D. et al. Investigation of lithium plating-stripping process in Li-ion batteries at low temperature using an electrochemical model. J. Electrochem. Soc. 165, A2167-A2167 (2018).

4. Arora, P., Doyle, M. \& White, R. E. Mathematical modeling of the lithium deposition overcharge reaction in lithium-ion batteries using carbon-based negative electrodes. $J$. Electrochem. Soc. 146, 3543-3553 (1999).

5. Usseglio-Viretta, F. L. E. et al. Resolving the discrepancy in tortuosity factor estimation for Li-ion battery electrodes through micro-macro modeling and experiment. $J$. Electrochem. Soc. 165, A3403-A3426 (2018).

6. Colclasure, A. M. et al. Electrode scale and electrolyte transport effects on extreme fast charging of lithium-ion cells. Electrochim. Acta 337, (2020). 